\title{
Visual Motion-Detection Circuits in Flies: Small-Field Retinotopic Elements Responding to Motion Are Evolutionarily Conserved across Taxa
}

\author{
Elke K. Buschbeck ${ }^{1}$ and Nicholas J. Strausfeld ${ }^{2}$ \\ ${ }^{1}$ Department of Ecology and Evolutionary Biology, and ${ }^{2}$ Arizona Research Laboratories, Division of Neurobiology, \\ University of Arizona, Tucson, Arizona 85721
}

\begin{abstract}
The Hassenstein-Reichardt autocorrelation model for motion computation was derived originally from studies of optomotor turning reactions of beetles and further refined from studies of houseflies. Its application for explaining a variety of optokinetic behaviors in other insects assumes that neural correlates to the model are principally similar across taxa. This account examines whether this assumption is warranted. The results demonstrate that an evolutionarily conserved subset of neurons corresponds to small retinotopic neurons implicated in motiondetecting circuits that link the retina to motion-sensitive
\end{abstract}

neuropils of the lobula plate. The occurrence of these neurons in basal groups suggests that they must have evolved at least 240 million years before the present time. Functional contiguity among the neurons is suggested by their having layer relationships that are independent of taxon-specific variations such as medulla stratification, the shape of terminals or dendrites, the presence of other taxon-specific neurons, or the absence of orientation-specific motion-sensitive levels in the lobula plate.

Key words: insect vision; evolution; elementary motion detection; Golgi method; neuroanatomy; Diptera
Ramon y Cajal's (1937) reference to the "exquisite adjustment" of the insect optic lobes reflected his conclusion that, of all the systems he had encountered, the insect visual pathways were the most structurally complex. The reason Ramon y Cajal gave was that insect optic lobes contain so many different, uniquely identifiable neurons. Therefore, by using modern methods of intracellular recordings and dye filling, such a system should be ideal for correlating the structure and function of neuronal morphologies with their role in visual processing.

Intracellular studies have focused on a tectal neuropil called the lobula plate (see Fig. 1), identifying large wide-field neurons in a few dipteran species. Activity-dependent uptake of ${ }^{3} \mathrm{H}-2$ deoxyglucose demonstrated the division of this neuropil into four direction- and orientation-specific layers (Buchner et al., 1984) corresponding to levels of wide-field cells that respond selectively to motion direction and orientation. As demonstrated by physiology and anatomy, the lobula plate collates information about motion and relays this to premotor neurons associated with head movements and flight direction.

For nearly 40 years the Hassenstein-Reichardt (1956) autocorrelation model has been employed to explain optomotor reactions

\footnotetext{
Received March 13, 1996; revised May 8, 1996; accepted May 9, 1996.

E.K.B. is supported by a grant from the National Science Foundation (DIR9113362 "Research Training Group: The Analysis of Biological Diversification") and was a recipient of a grant for Vector Biology from the MacArthur Foundation to the University of Arizona's Center for Insect Science. Field research in Costa Rica was supported by the Organization for Tropical Studies. This study is supported by a grant from the National Center for Research Resources (RR08688). Charles Hedgecock, Robert Gomez, and Carol Arakaki provided expert photographic and technical assistance. We thank Drs. Martina Wicklein and John K. Douglass for helpful discussions. Meredith Anderson allowed us to cite her results using antibodies raised against ChAT and ARD generously provided by Dr. P. Salvaterra (Beckman Research Institute of the City of Hope, Duarte, CA) and Dr. E. D. Gundelfinger (Federal Institute for Neurobiology, Magdeburg, Germany), respectively.

Correspondence should be addressed to Elke K. Buschbeck, Arizona Research Laboratories Division of Neurobiology, 611 Gould-Simpson Building, University of Arizona, Tucson, AZ 85721.

Copyright (C) 1996 Society for Neuroscience $0270-6474 / 96 / 164563-16 \$ 05.00 / 0$
}

in flies, beetles, moths, and locusts. With few exceptions (Torre and Poggio, 1978; Franceschini et al., 1989; Strausfeld and Lee, 1991), inputs to motion-sensitive tangential neurons are represented schematically by ensembles of Hassenstein and Reichardt elementary motion detectors (EMDs; Hausen and Egelhaaf, 1989). The general similarity of responses to optomotor stimuli by premotor descending neurons suggests that many other types of insects are supplied by analogous motion-detecting circuits (dragonflies, Olberg, 1981, 1986; moths, Rind, 1983; flies, Gronenberg and Strausfeld, 1990-1992; locusts, Hensler, 1992 and Frye and Olberg, 1995). If different insects respond similarly to optomotor stimuli, they could have evolved circuits for this function separately. If they share evolutionarily common circuits for motion detection, then this situation should be reflected by conserved cell types and arrangements across taxa.

To resolve this, we have performed a detailed comparative study across the Diptera, the phylogenetic relationships of which (Fig. 2) are well known from other criteria (McAlpine, 1989). We have searched for neurons that match small retinotopic neurons already identified in the green bottle fly Phaenicia, the intracellular responses of which suggest their involvement in motion computation (Douglass and Strausfeld, 1995, 1996). These neurons are the lamina efferents L4, L5, and T1, the transmedullary neurons Tm1 and iTm, and the bushy T-cells T4 and T5, terminating among motion-sensitive tangential neurons in the lobula plate.

The order Diptera is divided into two major divisions (Hennig, 1981): the usually nocturnal or crepuscular Nematocera (e.g., mosquitoes, midges, crane flies, all with long, multiannular antennae) and the usually diurnal Brachycera (e.g., hover flies, longlegged flies, robber flies, bottle flies, all with short, three segment antennae), the retina and lamina organization of which show specific morphological differences. In all, receptors sharing a common optical alignment have convergent axon projections (Braitenberg, 1967; Zeil, 1983a) to the same retinotopic subunit in 

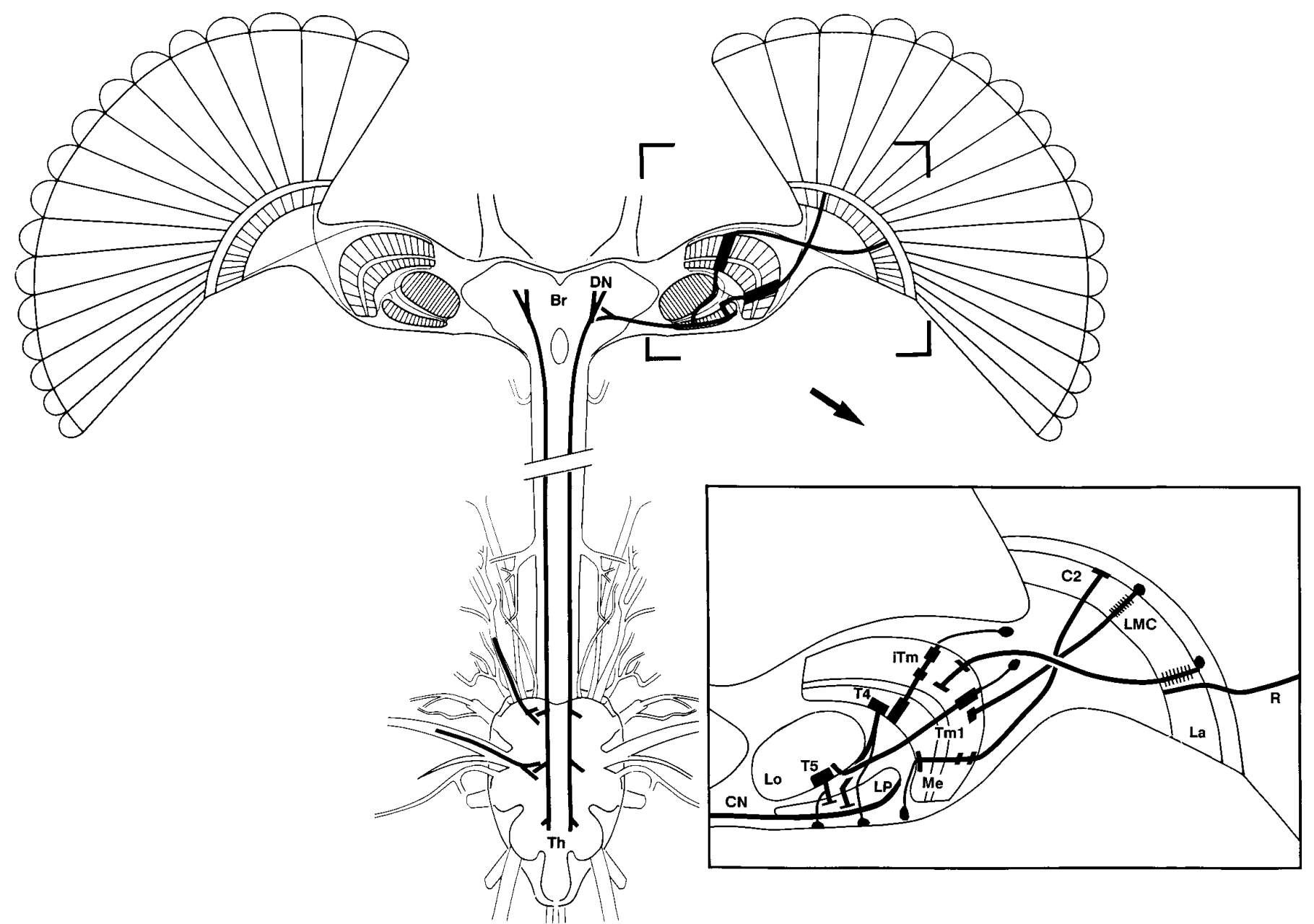

Figure 1. Schematic organization of the visual system of Diptera. Four retinotopic neuropils (lamina, $L a$; medulla, $M e$; lobula, $L o$; lobula plate, $L P$ ) provide outputs to the mid brain $(B r)$, which supply descending neurons $(D N)$ that terminate in motor centers of the thoracic ganglia $(T h)$. Neurons implicated in elementary motion detection are shown in the inset. These are R1-R6 photoreceptors $(R)$, large monopolar cells $(L M C s)$, the transmedullary cells (iTm and Tm1), the bushy T-cells (T4 and T5), and the centrifugal neuron (C2). The lobula plate sends axons of collator neurons $(C N)$ to the brain and contralateral lobula plate.

the lamina (optic cartridge; Boschek, 1971). Nematoceran flies typically have an open symmetrical distribution of photoreceptors sharing a common optical alignment (Kirschfeld and Wenk, 1976; Zeil, 1979) and providing branched receptor terminals (Melzer and Paulus, 1993). Brachycerans are united by their open trapezoidal distribution of photoreceptors sharing common optical alignments (Kirschfeld, 1967; Trujillo-Cenóz and Bernard, 1972) and unbranched terminals (Shaw, 1990). Among brachycerans, blow flies have been used extensively for vision research on nonvertebrate model systems. We have selected taxa for comparison that are representative of phylogenetic diversity such as the variety of body forms (Fig. 2), flight behaviors (Collett and Land, 1975; Zeil, 1983c, 1986; Tricca and Trujillo-Cenóz, 1980; Land, 1993a,b), luminance preferences, and transduction dynamics (Laughlin and Weckström, 1995). The present results demonstrate that neurons recently identified as being involved in the earliest computations of motion (Douglass and Strausfeld, 1995, 1996) are, indeed, evolutionarily conserved despite differences in receptor arrangements, terminal and synaptic organization in the outer plexiform layer (Shaw and Moore, 1989; Melzer and Paulus, 1993), and behavioral differences.

\section{MATERIALS AND METHODS}

Many of the species investigated, such as most asilids (Efferia) and bombyliids (Anthrax, Villa) were collected in the vicinity of Tucson, Arizona. Some of the bombyliid and syrphid (Eupeodes) specimens were collected in the Sonoran Desert of Mexico, close to Kino bay; others in Rara Avis-Selvatica and Estacion La Selva, Costa Rica (Ornidia obesa, Salpinogaster). Tabanids (Tabanus) were collected at the Gila National Forest, New Mexico; others (Scione maculipennis) at Rara Avis-Selvatica, Costa Rica, and in the vicinity of Bright, Victoria, Australia. Culicids (Aedis aegypti) were obtained from the laboratory colony of the Center of Insect Science, University of Arizona, and simuliids (Simulium vittatum) were provided from breeding facilities of Dr. E. Cupp, University of Arizona. Glossinids (Glossina morsitans) were kindly donated by Dr. S. Alksoy, Yale University. Phaenicia and Calliphora (Calliphoridae) were raised in our laboratory.

Golgi impregnation. Opened heads were fixed in $2.5 \%$ glutaraldehyde carried in cacodylate buffer. After 1-2 d, specimens were washed in $1.6 \%$ cacodylate buffer (Strausfeld, 1980) for $48 \mathrm{hr}$. Field specimens were stored up to several months in buffer and stained in addition to those treated after $48 \mathrm{hr}$. Specimens were transferred to $\mathrm{pH}$ 6.8-7.0 Sorensen's phosphate buffer, and after thorough washing, they were placed in $1 \%$ $\mathrm{OsO}_{4}$ diluted 1:20 with $2.5 \%$ potassium dichromate. After $4-10 \mathrm{~d}$ of chromation $\left(20\right.$ or $\left.4^{\circ} \mathrm{C}\right)$, the head capsule and compound eyes were opened further immediately before immersion in $0.75 \%$ silver nitrate in 


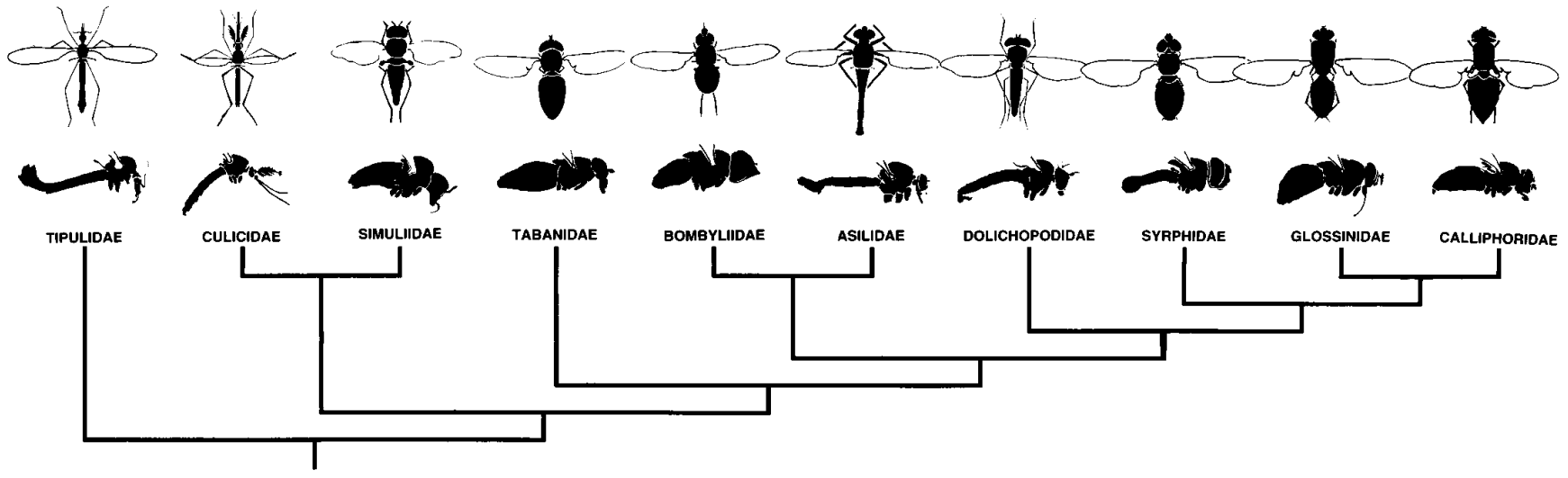

Figure 2. Phylogenetic relationships of nematoceran and brachyceran Diptera, based mostly on morphological characters and reconstructed after Wood and Borkent (1989), Woodly (1989), McAlpine (1989), Sinclair et al. (1993), and Cumming et al. (1995). Camera lucida drawings of insects illustrate the morphological variety of investigated taxa. Common names: tipulids, crane flies; culicids, mosquitoes; simuliids, black flies; tabanids, horseflies; bombyliids, bee-flies; dolichopodids, long-legged flies; syrphids, hover flies; glossinids, tsetse flies; and calliphorids, blow flies.

distilled water. The brains were dehydrated, embedded in soft Durcupan (Fluka, Mannheim, Germany), and serially sectioned at $30 \mu \mathrm{m}$.

Reduced silver staining. Tissue was fixed either in Gregory's (1980) synthetically aged Bouin's solution or in acetic acid-alcohol formalin. After fixation, the heads were washed in $70 \%$ ethanol and the brain was dissected from the head capsule, dehydrated, cleared in terpineol and then xylene, embedded in Paraplast plus (Corning, Corning, NY), and serially sectioned at $10 \mu \mathrm{m}$. Dewaxed sections were incubated for $24 \mathrm{hr}$ at $60^{\circ} \mathrm{C}$ in $1 \%$ silver proteinate (Roques, Paris, France) with the addition of 1-4 gm pure copper per $100 \mathrm{ml}$ solution. Afterward, tissue was conventionally treated after Bodian's (1937) original method.

Measurements. The depth at which each component of each cell type occurs in the medulla can be standardized as a percentage of total medulla depth (Strausfeld and Lee, 1991). Depths are given as a percentage of the total depth of either the outer or inner medulla layer, the two layers being separated by a tangential layer of axons in the serpentine layer (Figs. 7, 8). Scaling each cell type to a standardized medulla allows comparison of the depth of any arborizations of a neuron to any other. Interspecific comparisons can be standardized among species by using this principle. For example, in all species, the terminals of the L1 large lamina monopolar cell occur at the same depth as the outer dendritic processes of the intrinsic transmedullary neuron iTm.

Densitometry. At the light microscopic level, certain specializations on dipteran neurons are recognized as representing predominantly pre- or postsynaptic sites (Boschek, 1971; Strausfeld and Bassemir, 1985; Watson and Hardt, 1996). Postsynaptic specializations are regions from the axon or its collaterals that represent local swellings, varicosities, or beaded structures (blebs). Presynaptic specializations are minute, spine-like structures (or spicules, knobs), which arise from tapered branches, interpreted as dendritic. Certain nerve cells have processes that are invested with a mixture of both types of specializations. For densitometry, the specializations of neurons were drawn from serial optical sections (that is, collapsed to two dimensions) with a camera lucida extension and normalized to a standard medulla. Images were digitized, and the densities of pre- and postsynaptic specializations were measured with NIH Image (version 1.53). The raw images and the resultant density distributions were compared for lamina endings in the medulla, the dendrites of iTm and Tm1 medulla neurons, and the processes of the bushy T-cell T4.

\section{RESULTS}

\section{Architecture of the medulla neuropil}

The optic lobes consist of four successive neuropils: the lamina, medulla, lobula plate, and lobula (Fig. 1), all of which are organized into repeating retinotopic units. Retinotopy is conferred through to the lobula plate and lobula by small-field projection neurons, as schematized in Figure 1. Outputs from the optic lobes are relayed by collector neurons to a variety of brain areas, including those providing descending neurons to motor centers in the thoracic ganglia.
Reduced silver staining illustrates the basic organization of the medulla (Fig. 3). With the exception of simuliids and bibionids in which the upper and lower components of the sexually dimorphic eyes of males serve two distinct medullae (Zeil, 1983a,b; E. Buschbeck, unpublished data), in all those Diptera that we have investigated the medulla is organized as two concentric layers: in brachycerans, an outer two-thirds (or outer half in the Nematocera) is separated from an inner third by a stratum of large tangential axons that comprise the serpentine layer. In each species, the axons of retinotopic neurons that project through the medulla (transmedullary cells) are clustered into columns. These are traversed by successive levels of synaptic plexi that are derived from the dendrites and axon collaterals of transmedullary cells, amacrines, and wide-field tangential neurons (Strausfeld, 1970). The latter are connected to axons that enter or leave the medulla by its serpentine layer.

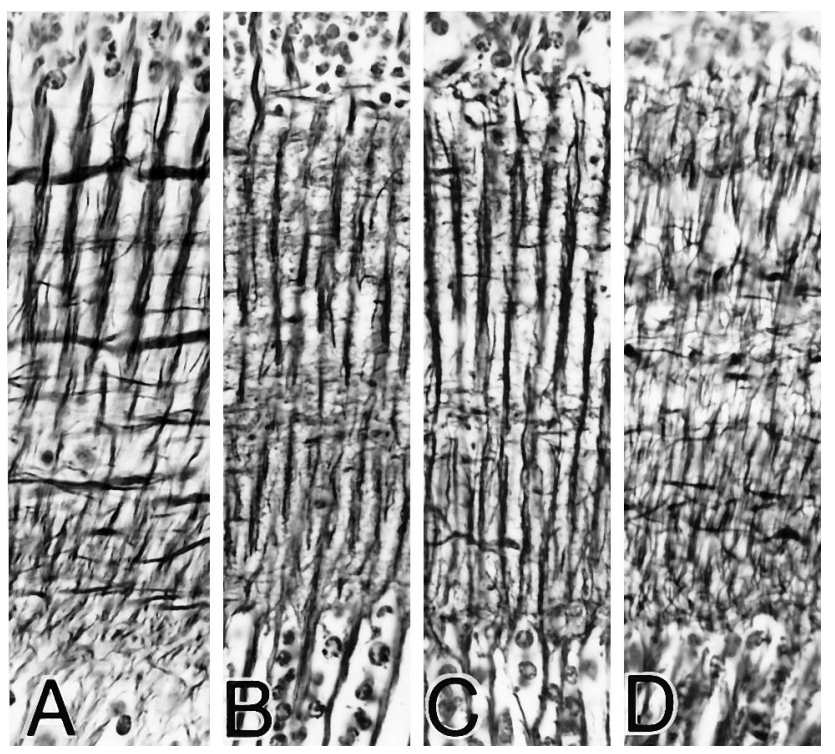

Figure 3. Reduced silver staining of cross-sections through the medulla of four brachyceran flies. $A$, Calliphorid; $B$, syrphid; $C$, bombyliid; $D$, tabanid. Images are scaled to equal size for comparison. Differences are in the relative depths of analogous strata. However, as demonstrated in Figures 4-6, these do not reflect taxonomic differences between cell relationships. 


\section{Stratification within the medulla: determining layer relationships}

The geometry, outline, and depth at which the specializations of a neuron (branches, spines, varicosities, etc.) occur confer its unique morphological identity (Fig. 4). The coincidence of such specializations from two or more neurons at specific depths suggests levels at which synaptic interactions occur. However, each species of fly has its own distinctive medulla, as demonstrated by differences in the relative depths of different strata in Bodian staining (Fig. 3), as well as in the occurrence of many cell types that have their own species-specific morphologies (Ramon y Cajal and Sanchez, 1915; Strausfeld, 1970, 1976). If, independent of such differences, the same combination of certain neurons occurs across taxa, then such an occurrence can be taken as an indication of computational and/or phylogenetic conservation. In the following sections we shall describe combinations of neurons, all associated with the lobula plate, that have invariant depth relationships.

Analyses of depth relationships depend, in the first instance, on careful comparisons of Golgi-impregnated neurons that can be followed throughout their entire length through the medulla within the depth of a single section, usually no thicker than $20 \mu \mathrm{m}$ (Fig. 5). This condition ensures that the neuron can be reconstructed by camera lucida in its upright columnar disposition while the outer and inner margins of the medulla are visualized. Neurons have been reconstructed and compared from frontal sections in which the dendrites and terminals extend vertically through the retinotopic mosaic, normal to the internal representation of the visual horizon. Comparisons among neurons are from images normalized to a standard medulla depth, equivalent to $100 \mu \mathrm{m}$. Controlling for possible differences in layer relationships among representatives of the same morphological cell type has demonstrated that, irrespective of the local depth in the medulla, any species of neuron has a characteristic relationship to it (Strausfeld, 1971).

Relative depth relationships among neurons have been evaluated by measuring examples of any cell type, averaging the levels of their specializations, and expressing these as percentage depths (Fig. 6). Thus, whereas there may be occasional variations in the depth of penetration of dendrites of the transmedullary iTm, for example, these match slight variations in the depth of penetration by the L1 terminal. Although important differences exist between nematoceran and brachyceran Diptera, repeated sampling of specific morphological cell types showed negligible intraspecific variations. Densitometric plots of spines and varicosities (Fig. 7) resolved local variations within layers of pre- and postsynaptic specializations and provided information about profile densities. For example, these plots demonstrated that, within the outer medullas of four taxa, the presynaptic specializations of the lamina efferents L1, L2, and L3 matched the levels of the postsynaptic specializations of the two narrow-field transmedullary cells, iTm and Tm1 (see below).

\section{Taxonomic constancy of first-order afferents and their levels of termination in the medulla}

Each retinal ommatidium provides six "scotopic" receptors (R1R6) having uniform spectral sensitivity maxima (Hardie, 1979) and operating over a wide intensity range (for reviews, see Laughlin, 1984; Shaw, 1989). R1-R6 share the same optical alignment (a visual sampling unit; Franceschini, 1975) and terminate in a columnar subunit (an optic cartridge) that provides efferents (lamina monopolar cells) to the medulla. Each ommatidium also provides a parallel receptor channel composed of a pair of photopic blue- and UV-sensitive photoreceptors, R7 and R8, which operate at higher light intensities (Hardie, 1979) and terminate in the medulla.

Each optic cartridge provides three large monopolar cells (LMCs) that are postsynaptic to R1-R6 photoreceptor terminals. Two smaller monopolar cells, L4 and L5 (Strausfeld, 1971), are postsynaptic to local interneurons in the lamina. Two of the LMCs look almost identical, having dendritic spines arranged throughout the depth of the optic cartridge (Strausfeld, 1971). Only the medulla terminals of these cells distinguish them as two distinct cell types; L1 is usually bistratified in Brachyceran flies, and L2 is

Figure 4. Layer constancy within a taxon is demonstrated in this tabanid with mass impregnation by the Golgi method. This section shows several LMC terminals $(L 1, L 2)$, the endings of the lamina monopolar cell $L 5$, and several type $i T m$ (transmedullary neurons). Different individuals of each cell type show the remarkable morphological constancy.

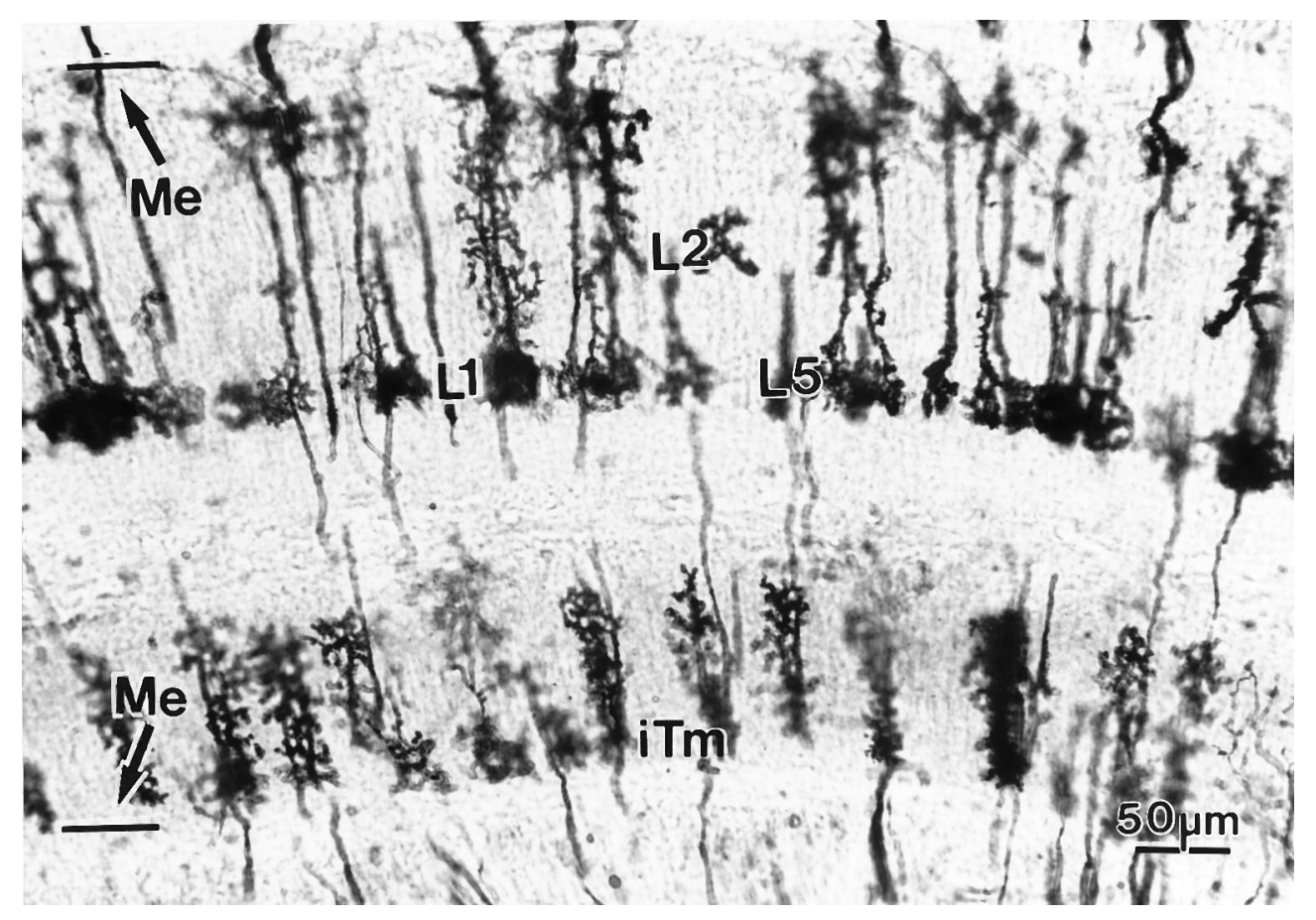



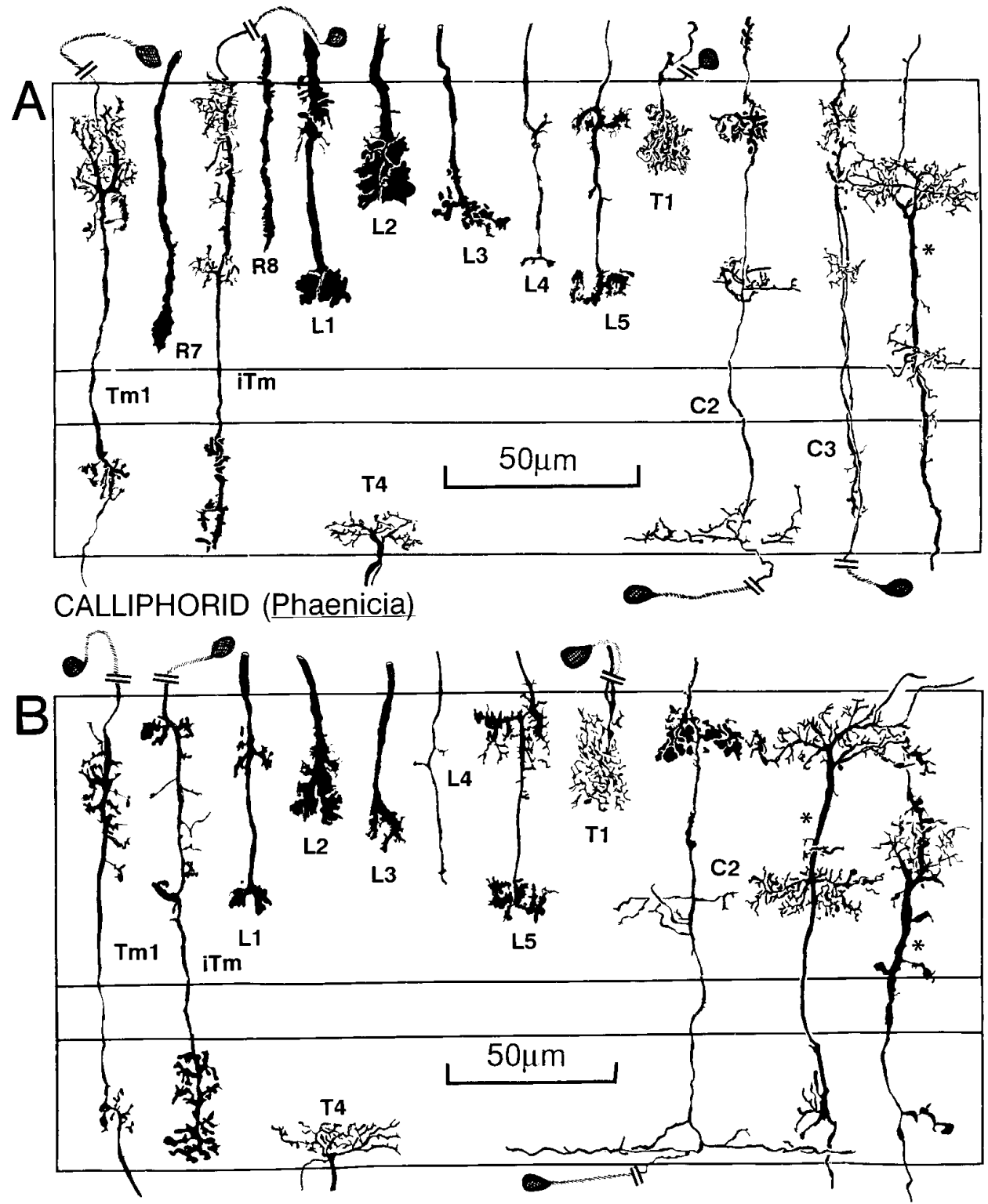

\section{GLOSSINID}

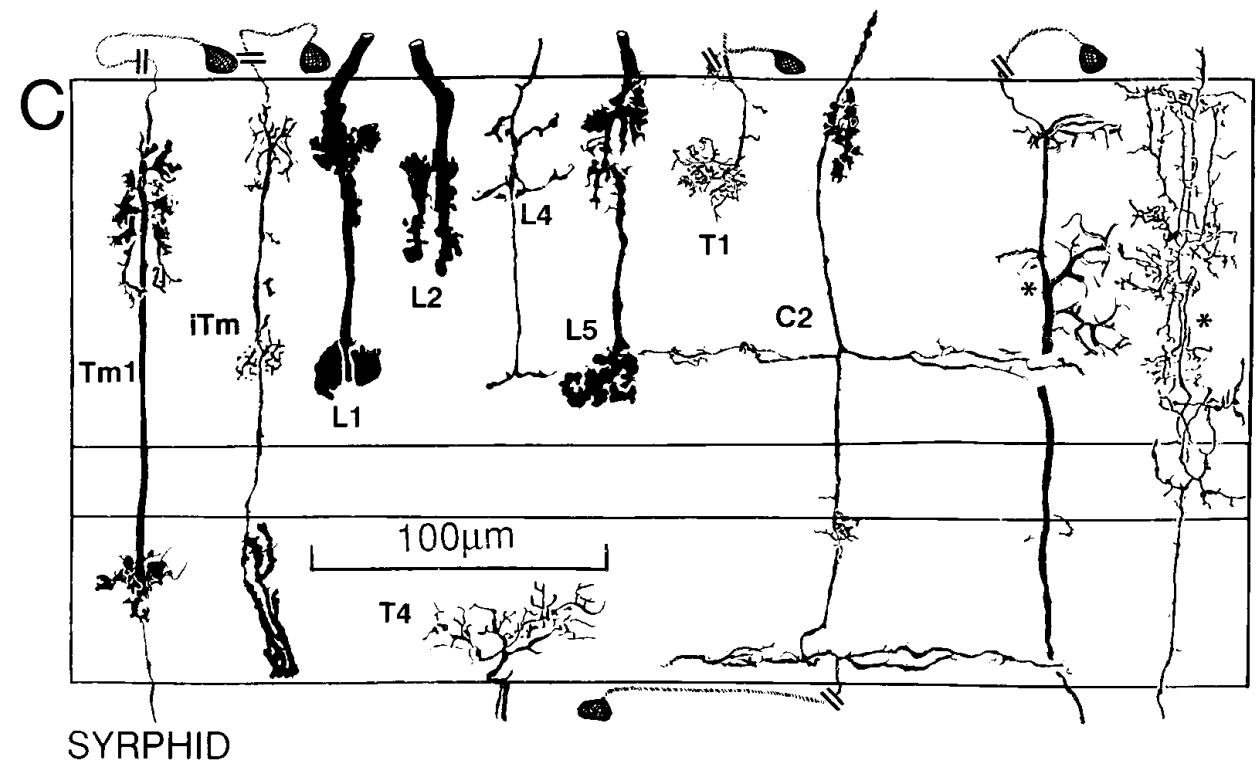

Figure 5. Reconstructions of conserved medulla neurons in seven different brachyceran species. Although distinct species-specific differences can be observed with respect to features, such as the arrangement of L1 varicosities, the characteristic Gestalten of a subset of medulla elements (L1, L2, L3, L4, L5, $T m 1, i T m, C 2$, and $T 4$ ) are conserved across taxa. In contrast to the transmedullary cells $\mathrm{iTm}$ and $\mathrm{Tm} 1$ that are associated with $\mathrm{T} 4$ and T5 (see Fig. 9), other retinotopic transmedullary neurons destined for the lobula elements (indicated by asterisks to the right of each figure) have been found in, at most, only two of the investigated taxa and thus seem to be less strongly conserved than neurons serving motion computation. Figure 5 continues. 

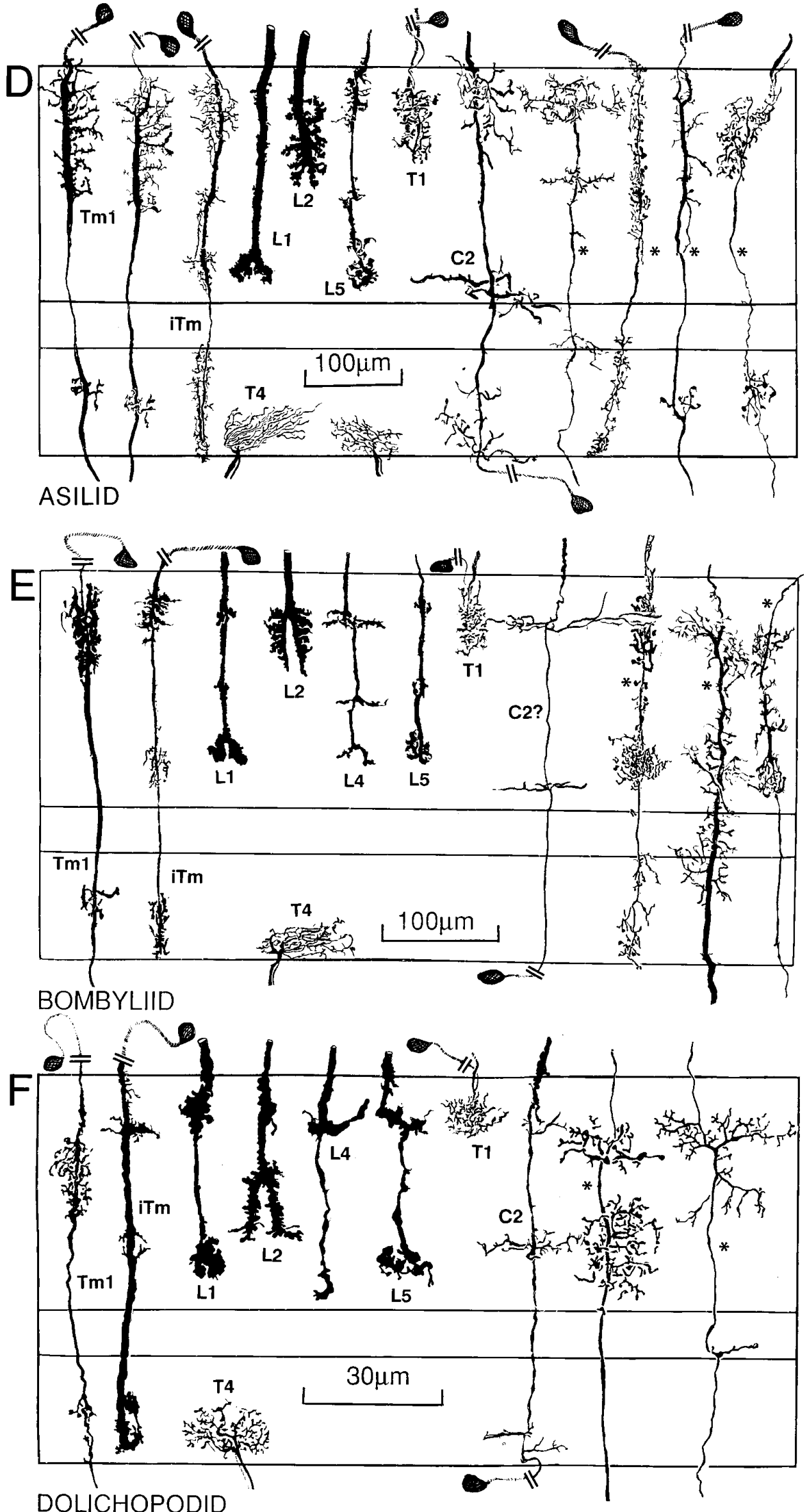


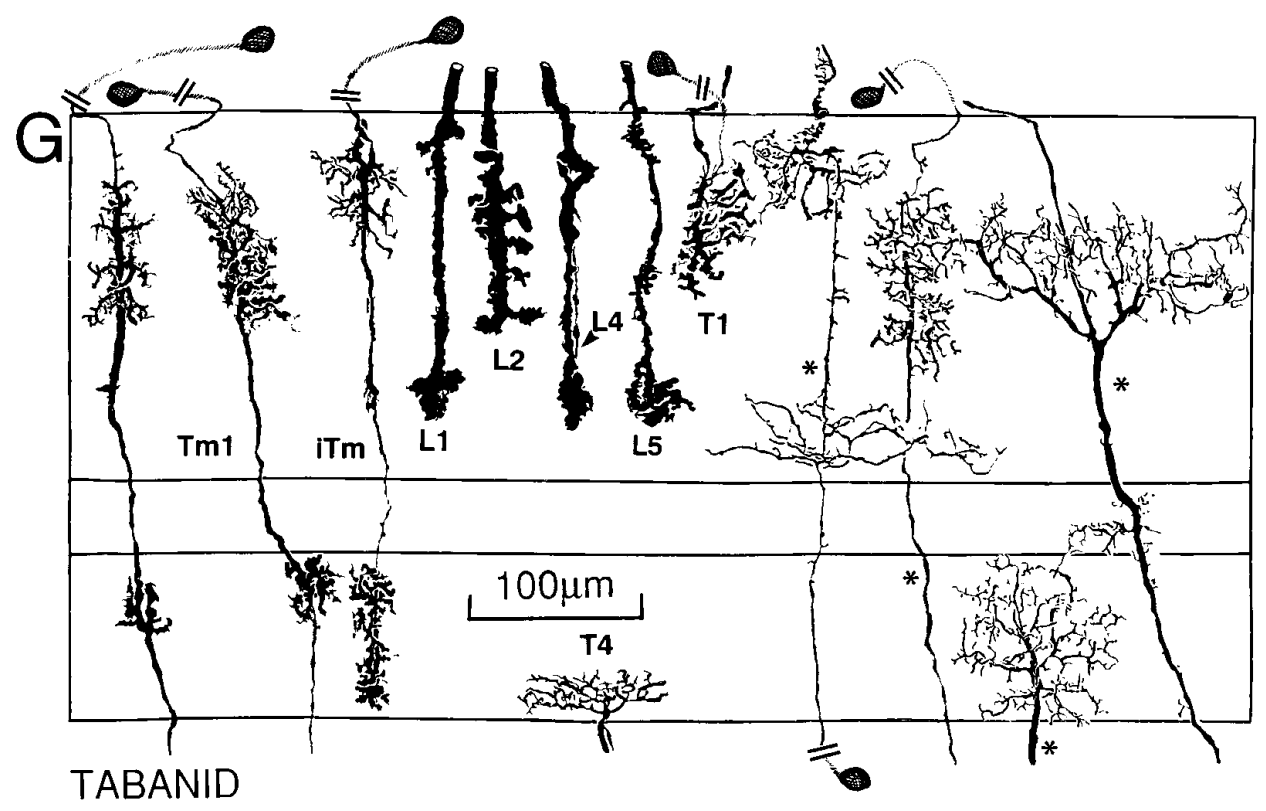

Figure 5 continued.

unistratified (Fig. 5). In the suborder Nematocera, culicids and simuliids both have stratified L1 and L2 endings, but, as in the Brachycera, these terminate at a deeper and shallower level, respectively (Fig. 8; see also Melzer and Paulus, 1993). In the brachyceran calliphorids (Fig. $5 A$ ) as well as in glossinids and syrphids (Fig. 5B,C), the L1 neuron endings are characterized by swellings close to the outer border of the medulla and have a bilobate terminal situated between the 75 and $95 \%$ depth levels of the outer layer of the medulla. In asilids, bombyliids, and dolichopodids (Fig. 5D,E,F), the axis fiber linking the outer and inner segments of the L1 terminal provides small, bouton-like swellings, the levels of which correspond to varicosities in the L4 and L5 monopolars (see below). Tabanids have a similar organization (Fig. 5G), with the L1 ending trilobed. Comparisons across taxa demonstrate that the deep lobes of L1 coincide with the inner specializations of L5. When L5 and L1 neurons are impregnated in the same column, they cannot be resolved individually, except at their origins in the lamina. The inner specializations of $\mathrm{L} 1$ and L5 are aligned with a stratum of dendrites arising from the intrinsic transmedullary cell iTm, which will be discussed in greater detail later. Except in simuliids and culicids (Fig. 8), this relationship is common to all families, including the tabanids in which the second stratum of iTm is much reduced, being represented only by a cluster of short spines (Fig. $5 G$ ).

The bilobed L2 terminals of calliphorids (Fig. $5 A$ ) consist of a multitude of varicosities. They are similar to the L2 endings of glossinids (Fig. 5B), in contrast with syrphids, bombyliids, and dolichopodids (Fig. 5C,E,F) in which L2 endings strongly bifurcate, each branch giving rise to varicosities extending laterally. In asilids (Fig. 5D), the L2 ending first gives rise to lateral varicosities and bifurcates only at its tip. In tabanids, the entire depth of the L2 ending consists of a comb-like arrangement of varicosities (Fig. $5 G)$ as is seen also in certain tipulids (crane flies; Figs. 2, 8) (cf. Melzer and Paulus, 1993). This latter taxon differs from other nematoceran Diptera in which L2 has a simple, plug-like ending decorated with short protuberances (Fig. 8).

Even in culicids and simuliids (Fig. 8), the depth relationships of L2 are well defined, corresponding to the level of the narrow dendritic field of the Tm1 transmedullary neuron. That L2 is functionally associated with $\mathrm{Tm} 1$ is suggested by taxonomic variations in the shapes of the L2 terminal, corresponding to variations in the profile of the Tm1 dendritic tree. In calliphorids (Fig. $5 A$ ), the bilobed morphology of $\mathrm{L} 2$ is reflected by the bilateral division of the Tm1 dendrites. In asilids and tabanids, the more diffuse and comb-like arrangement of L2 varicosities matches the more diffuse arrangement of Tm1 dendrites at that level (Fig. $5 D, G)$. In bombyliids and dolichopodids, the Tm1 dendrites are densely clustered, corresponding to the relatively short depth of L2 penetration into the medulla and the concentration of its terminal varicosities (Fig. $5 E, F$ ).

In addition to monopolar cells, each retinotopic unit (optic cartridge) in the lamina provides R1-R6 input to a basket-like dendritic arbor belonging to a lamina-to-medulla $\mathrm{T} 1$ neuron. These cells arise from perikarya above the outer surface of the medulla (Strausfeld, 1970) and provide a tight cluster of varicosities to the medulla at the same level as that of the L2 terminals. Each T1 cell is also postsynaptic to processes of several type 1 amacrine cells (Campos-Ortega and Strausfeld, 1972). Amacrines may provide inhibitory input to $\mathrm{T} 1$, which, typically, has a narrower receptive field than the receptors presynaptic to it (Järvilheto and Zettler, 1973). T1 is modulated also by motion stimuli, although its motion responses were weaker than they were to flicker (Douglass and Strausfeld, 1995).

T1 neurons have been identified in all the brachyceran Diptera (Fig. 5) but, thus far, have not been seen in the Nematocera. T1 endings in the medulla reside at the same level as the terminals of L2 and, when impregnated together in the same medulla column, $\mathrm{T} 1$ and L2 are indistinguishable. Combined Golgi impregnation and electron microscopy of Musca also show L2 heavily invested by T1 varicosities (N. J. Strausfeld, unpublished observations). Taxon-specific differences in the depth of penetration by $\mathrm{T} 1$ invariably match the level of the Tm1 outer dendrites and the L2 terminals, suggesting that these three elements are functionally related.

\section{First-order local interneurons}

Small monopolar cells (SMCs) are local interneurons arising from the lamina but that are not postsynaptic to photoreceptors. In- 


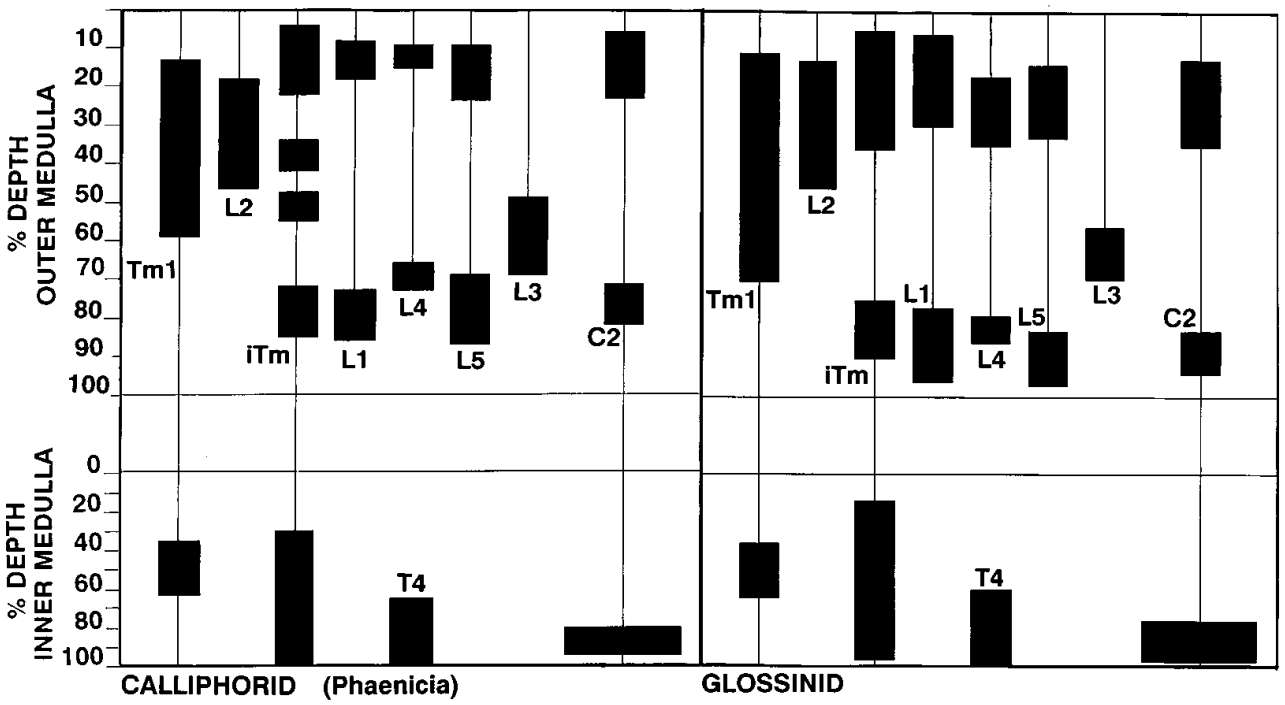

Figure 6. Conservation of depth relationships between specific medulla neurons involved in motion computation. Because of small disparities in the sectioning plane, some of the Golgi reconstructions of Figure 4 show minor discrepancies from their precise absolute depths. Here, depth measurements of several exemplary cells demonstrate the relative depths of specializations for each species of neurons to show that layer relationships are strictly conserved between taxa. For example, in each case the dendritic arborizations of $T m 1$ correlate in depth with $L 2$ terminals. The bilayered specializations of $L 1$ coincide with those of $L 4, L 5, C 2$, and $i T m$, even in bombyliids, in which in all but $C 2$ an additional layer of specializations can be observed.

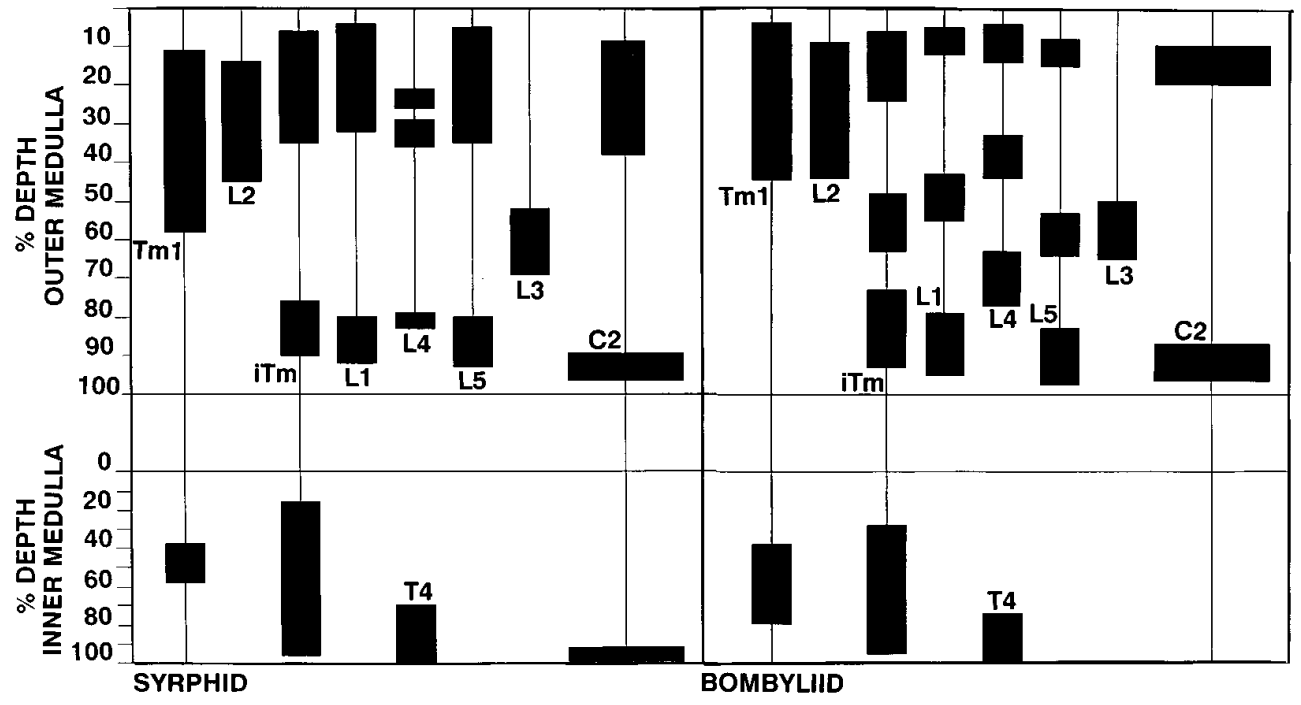

stead, they receive their inputs from lamina amacrines and centrifugal cells (Strausfeld and Nässel, 1980). Unlike the LMCs, L5 and possibly L4 distinguish flicker from motion (Douglass and Strausfeld, 1995). The idea that L4 might play a role in motion computation has always been attractive, because previous studies (Strausfeld and Braitenberg, 1970) demonstrated that L4 cells provide an orthogonal network of collaterals that, in the lamina, provide pre- and postsynaptic connections among LMCs (Strausfeld and Campos-Ortega, 1973). Observations of Musca domestica have shown that L4 terminals also provide lateral connections in the medulla; the columns are closer and the terminals of L4 branch at two or three levels (Strausfeld and Campos-Ortega, 1973). L4 endings show minor taxonomic variation. In Calliphora, each L4 provides a small collateral to two neighboring columns at the 5-8\% depth of the medulla (Fig. 5A). Its terminal, at the $75 \%$ depth, provides one or two short-knobbed branches within the column receiving the axon. Similarly, glossinid L4s have slender terminals, each providing two distal collaterals that extend to the two neighboring columns, with the deeper component remaining in its parent column. In contrast, the L4 terminals of bombyliids, syrphids, and dolichopodids all have stouter axon diameters; in syrphids and bombyliids, they provide stratified collaterals that project orthogonally to the flanking columns. Typically, the outer collaterals of L4 in the medulla reside at the same level as the distal swellings of the L1 monopolar cell terminals. L4 endings terminate just above the inner, lobed ending of L1 (Fig. 9). This organization is consistent among the Brachycera, with the exception of asilids, in which L4 neurons have not yet been found.

The position of the L5 monopolar cell in the optomotor pathway is enigmatic. In the lamina of muscids, calliphorids, syrphids, and drosophilids (Strausfeld, 1971; Fischbach and Dittrich, 1989), this neuron has but a single spine that, in Musca domestica, is postsynaptic to type 2 tangential amacrine processes in the plexiform layer of the lamina (Strausfeld and Nässel, 1980). L5 thus receives no direct input from receptors and serves the role of an interneuron, yet it is modulated nondirectionally by motion (Douglass and Strausfeld, 1995). In all of the Brachycera, the ending of this neuron mimics that of the L1 monopolar cell, its levels reflecting the bistratified nature of L1 (Figs. 6A,D, 7). When impregnated together in the same medulla column, L1 and L5 are indistinguishable (Fig. 9).

\section{The retinotopic centrifugal neuron $\mathrm{C2}$ : its relationship with efferents from the lamina}

Two classes of centrifugal cells link the medulla with the lamina. These are the small retinotopic neurons C2 and C3 and the type 

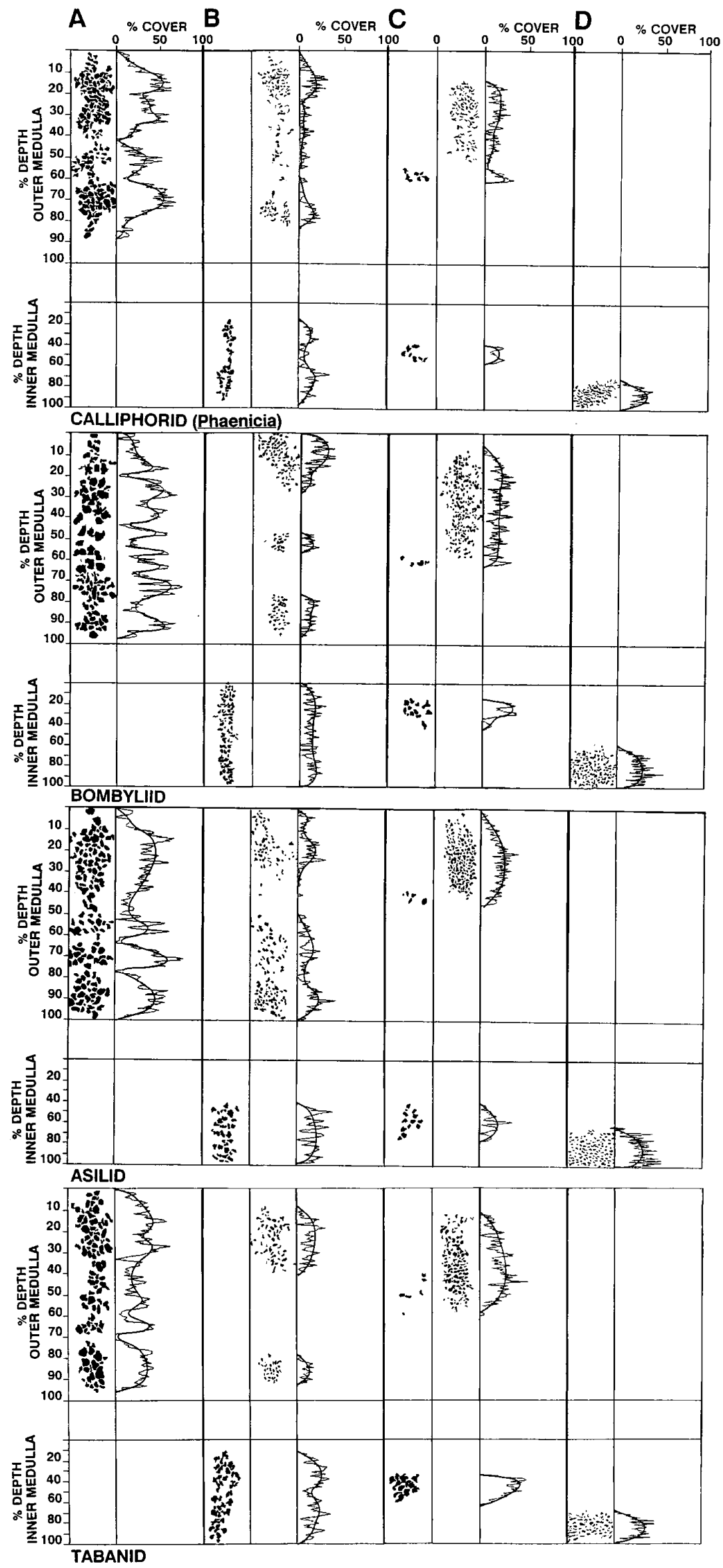

Figure 7. Densitometric analysis of varicose and spiny decorations on medullary neurons, illustrating similarities in profile densities. This method, used for analyzing layer relationships in the calliphorid Sarcophaga bullata (see Strausfeld and Lee, 1993) is used here for four additional taxa. In each case, the first column $(A)$ illustrates medulla inputs; these are the LMCs, L4, L5, and T1 and the photoreceptors R7 and R8. The second and third columns show the densities of varicose and spiny processes of $\operatorname{iTm}(B)$ and $\operatorname{Tm} 1(C)$. D, The bushy arborization of T4. Comparisons of the output specializations of $\mathrm{iTm}$ and $\mathrm{Tm} 1$ in the inner medulla demonstrate the relationship of $\mathrm{i} \mathrm{Tm}$, not $\mathrm{Tm} 1$, to T4. Jagged lines indicate changes in density; smooth lines indicate the average. 


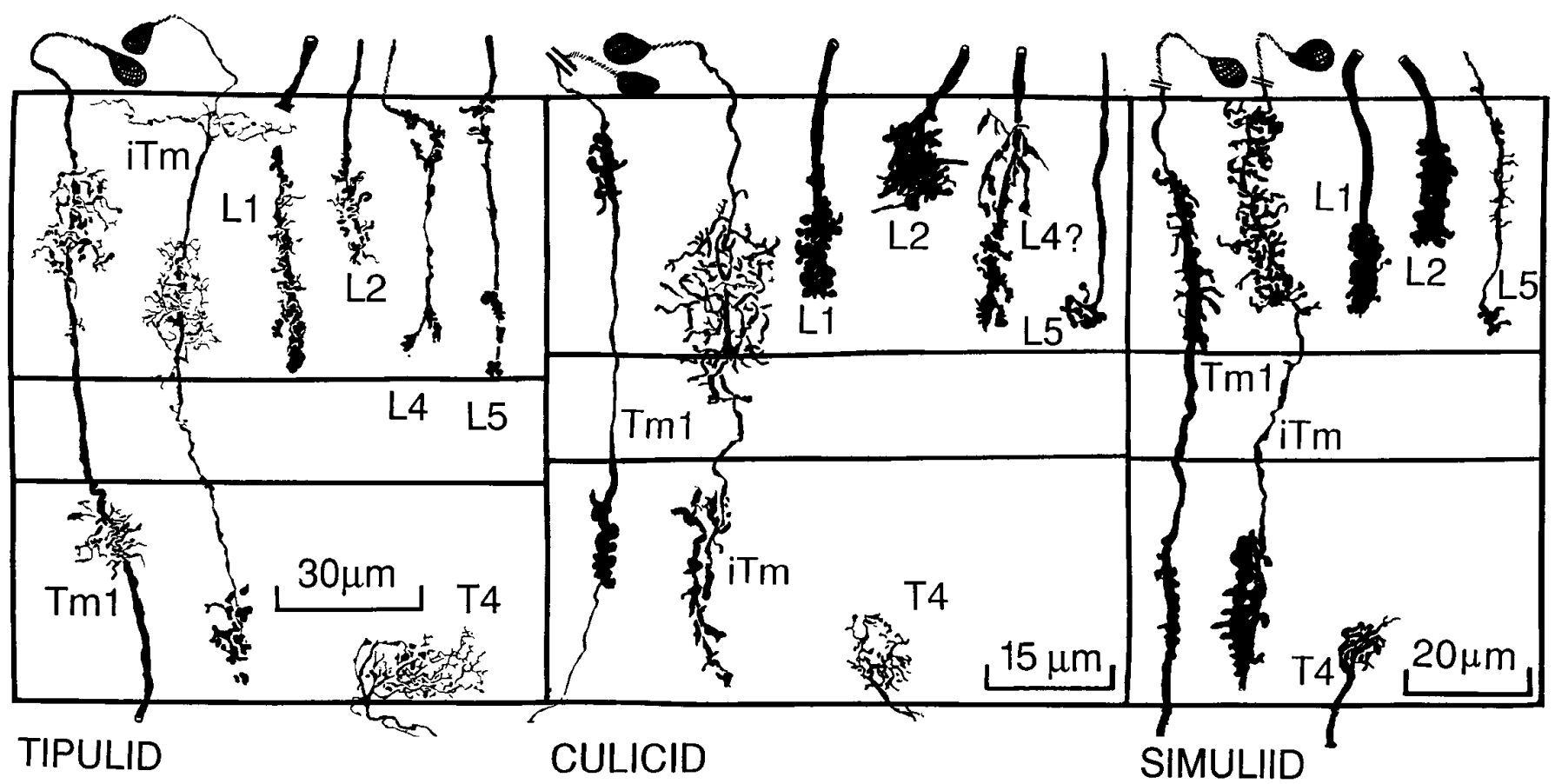

Figure 8. Reconstruction of conserved medulla neurons in three different nematoceran species, based on Golgi impregnation. As in Figure 4, the basic shape and characteristic Gestalt of a subset of medullary neurons remains conserved in these taxa, except that the tipulid iTm has an extra and extremely thin layer of distal processes extending to neighboring columns. However, the basic layer relationships among individual neurons, although a little less precise than in brachyceran species, generally are conserved.

1 and 2 lamina tangential cells. Their functional centrifugality is demonstrated by their varicose or blebbed presynaptic terminals in the lamina. $\mathrm{C} 2, \mathrm{C} 3$, and the type 1 lamina tangential are presynaptic to LMCs (Strausfeld and Nässel, 1980); the type 2 tangential contacts L5 and parts of the type 1 amacrine. Here we consider the organization of $\mathrm{C} 2$, a neuron that, in Phaenicia, is the most distal element to show orientation-selective responses to motion stimuli (Douglass and Strausfeld, 1995). The neuron is exceptionally interesting with respect to its possible role in motion computation; in cyclorrhaphan flies, it has two levels of presynaptic specializations. In the medulla, its outer swellings (or processes, depending on the taxon) are situated in a superficial stratum that reacts strongly to antibodies raised against ChAT and ARD [the latter, an Ach receptor protein (see Acknowledgments); M. C. Anderson and N. J. Strausfeld, unpublished observations]. In the lamina, $\mathrm{C} 2$ has GABAergic terminals presynaptic to LMCs just above their dendrites (Meyer et al., 1986).

C2 neurons originate from a cluster of cell bodies situated between the inner medulla and the outer edge of the lobula plate (Fig. 1). In calliphorids, glossinids, and syrphids (Fig. 5A-C), the distal medulla specializations of $\mathrm{C} 2$ are obviously varicose. At the same level in asilids and tabanids (Fig. $5 G$ ), C2 provides a rich collateral arborization that overlaps much of the L2 terminal and unambiguously invades at least one neighboring retinotopic column, thus supporting confocal microscope observations in Phaenicia and demonstrating that the much narrower $\mathrm{C} 2$ specialization also links pairs of columns within the outermost medulla stratum (Douglass and Strausfeld, 1995). In dolichopodids (Fig. $5 F$ ), $\mathrm{C} 2$ provides some sparse lateral branches that, likewise, reach the neighboring column. In all Brachycera, the $\mathrm{C} 2$ axon exhibits varicosities for a distance of $10-20 \mu \mathrm{m}$ above the outer medulla layer along its passage out to the lamina. In bombyliids (bee-flies), unlike other brachycerans, C2 neurons also have a narrow layer of vertically oriented processes at the L2 level, suggesting a major difference in this taxon.

In addition to its GABAergic terminals in the lamina, a diagnostic feature of a $\mathrm{C} 2$ neuron is its vertically oriented dendrites in the medulla. In all brachycerans these are situated at the same level as the deep terminal of L1 (between 75 and $95 \%$ of the depth of the outer medulla). With the exception of bombyliids, C2 neurons have the same vertical extent of dendrites situated at the inner margin of the inner layer of the medulla. In contrast to their presence in Brachycera, $\mathrm{C} 2$ neurons have not been identified yet in nematocerans.

\section{Conserved medulla neurons: relays between lamina inputs and neurons supplying motion-sensitive levels of the lobula plate}

There is great variety among the forms of transmedullary cellsretinotopic efferent neurons that project through the medulla. Many of those having wide-field dendrites and slender axons are typical of a family or species (Strausfeld, 1970, 1976; Fischbach and Dittrich, 1989; Strausfeld and Lee, 1991). Such neurons (see examples in Fig. 5A-G) project their axons to deep levels of the lobula. They are distinguished from two types of small-field retinotopic neurons, which have dendritic fields restricted to their parent column and have thicker axons. One cell type, iTm, terminates in the inner medulla layer; the other, Tm1, terminates within a superficial stratum of the lobula. Recordings from iTm show that it does not distinguish the direction of motion, whereas Tm1 responses are modulated by motion direction (Douglass and Strausfeld, 1995). The two cell types are ubiquitous, being present both in Brachycera and the more basal nematoceran taxa (Figs. 5, 8).

Although the dendritic levels of iTm and Tm1 to some extent overlap (Fig. 6), their terminals segregate to two completely 

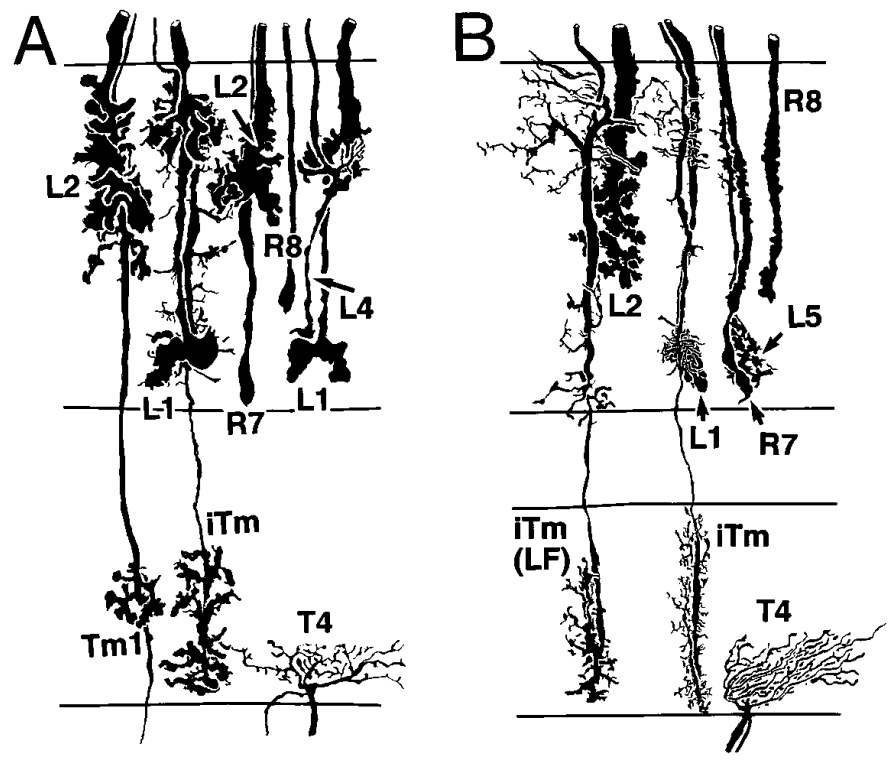

Figure 9. Camera lucida drawings showing coimpregnation of medulla neurons in glossinids $(A)$ and asilids $(B)$. Resolution of neurons in a single column, or direct neighbors, verifies the relative depth relationships of neurons to each other. In both species $L 1$ has been coimpregnated with $i T m$, illustrating the tight overlap of their neural processes. In asilids, in addition to the $i T m$ neuron restricted to a single column, these taxa possess a neuron $(i T m[L F])$ with similar terminal arrangements in the inner medulla but having dendrites with a larger field reaching neighboring cartridges.

different levels. In calliphorids, iTm ends as a bistratified recurrent terminal within the inner medulla, whereas Tm1 has a simple plug-like varicosity in the outermost stratum of the lobula. These two layers contain the dendrites of bushy T-cells (Strausfeld, 1970), the only small-field retinotopic neurons to project from the medulla terminals exclusively into the lobula plate. T5, from the lobula, responds to motion in a directionally selective manner (Douglass and Strausfeld, 1995), whereas T4, from the medulla, is not directionally selective to motion (Douglass and Strausfeld, 1996).

In all taxa, T4 dendrites reside at the $70-100 \%$ level of the inner medulla. T5 dendrites reside exclusively within the $0-15 \%$ level of the lobula. T4 dendrites overlap the innermost varicosities of iTm. T5 dendrites are visited exclusively by the terminals of Tm1. In calliphorids, iTm has narrow-field bistratified dendrites in the outer medulla, the layering of which coincides with the bistratification of the L1 terminal. This relationship generally holds across the Brachycera (except in asilids; see Fig. 9 and Discussion) at $4-32 \%$, and $75-95 \%$ of the outer medulla. In the Nematocera (Fig. 8), these relationships are less obvious. In tipulids (Fig. 7), iTm has a narrow outer layer of dendrites and a second, somewhat deeper layer that coincides with the terminals of L2 and the stratified diffuse endings of L1. In culicids, the deep unistratified terminal of L1 coincides in depth with the diffuse terminal of iTm, and in simuliids, the depth of the iTm dendrites extends from the 0 to the $90 \%$ depth of the outer medulla; that is, the depth is coincident with the two separate levels of L1 and L2 endings.

In calliphorids (e.g., Phaenicia), syrphids (Fig. 5C), asilids (Fig. $5 D$ ), and tabanids (Fig. $5 G$ ), the iTm terminal is divided subtly into two components. At the $15-65 \%$ level, it provides short processes decorated with small boutons, and, immediately proxi- mal to these at the $70-100 \%$ level, it gives rise to irregular varicosities that coincide with the T4 dendrites (Fig. 5A) and that often arise from a recurrent bend in the iTm axon terminal. Two extremes of this arrangement are shown by glossinids (Fig. $5 B$ ), in which the division of these two levels is exaggerated, and in dolichopodids (Fig. $5 F$ ), in which iTm provides only one level of terminals at the level of $\mathrm{T} 4$ dendrites.

These observations suggest that iTm provides the conserved pathway from L1 to T4. There is just as persuasive evidence that Tm1 carries the afferent supply to T5 from L2. In all taxa, the Tm1 dendrites in the outer medulla mimic the spread and the depth of the L2 terminal (Figs. 5, 8). In both nematocerans and brachycerans, Tm1 axons project from the medulla across the second optic chiasma to T5 dendrites at corresponding retinotopic positions in the outer stratum of the lobula. Although this layer is perforated by many other transmedullary cell axons, these target deeper lobula levels, ending among columnar efferents. In Nematocera and Brachycera (Figs. 5, 8), Tm1 provides a set of collaterals within the inner medulla. However, depth averaging (Fig. 6) and densitometry (Fig. 7) demonstrate that these generally reside above the level of $\mathrm{T} 4$ dendrites at a height that matches a widefield amacrine cell recorded and filled in Phaenicia (Douglass and Strausfeld, 1996). Only in dolichopodids and glossinids does there appear to be a slight overlap between Tm1 and T4 (Fig. 5B). However, even in these taxa, averaging and densitometric analysis (data not shown) demonstrate that $\mathrm{Tm} 1$ specializations do not overlap T4 dendrites and that, as in other taxa, they are the deepest varicose elements of iTm that reside at the T4 level.

\section{Bushy T-cells and motion-sensitive wide-field neurons in lobula plate}

T4 and T5 neurons are characterized by their branched, bushy dendrites. As described from Sarcophaga (Strausfeld and Lee, 1991), bushy T-cell dendrites are morphologically asymmetric, the longer processes having more spines and fewer varicosities and the shorter ones having more varicosities than spines. However, symmetric trees have been identified since that time within the same clade - a monophyletic group (Fig. 10I-K) or species (Fig. $11 A$ ) - suggesting that bushy T-cells may be divisible into two morphological subclasses. In species of Nematocera and in tabanids (Fig. 9H), two taxa having close phylogenetic positions (Fig. 2), the T5 dendrites have unusually long and narrow dendritic trees. In the phylogenetically allied simuliids and culicids (Fig. 2), T4 dendritic trees are symmetrical but otherwise are disposed like those in larger diurnal flies. In the remaining Brachycera, T5 neurons are usually asymmetric and compressed (Fig. 10A-F).

T4 and T5 terminate as sparsely bifurcated varicose branches that project tangentially in the lobula plate, parallel with its surfaces and generally extended along the vertical axis of the retinotopic mosaic. As described from Musca, Calliphora (Strausfeld, 1970, 1976), and Drosophila (Fischbach and Dittrich, 1989), bushy T-cells can terminate at any one of four motion-sensitive levels in the lobula plate (see Discussion). Golgi-electron microscopy of a Sarcophaga T4 shows that it is presynaptic to a dendritic branch of the horizontal motion-sensitive (HS) neurons (Strausfeld and Lee, 1991). Electron microscopical observations also suggest that T4 and T5 make similar connections with vertical motion-sensitive neurons (VS; Hengstenberg, 1982). A naturally occurring "control" of the layered relationships between bushy T-cells and HS and VS neurons is provided by asilids, in which the lobula plate lacks neurons that morphologically correspond to VS cells in other brachycerans (Buschbeck and Strausfeld, 1993). 


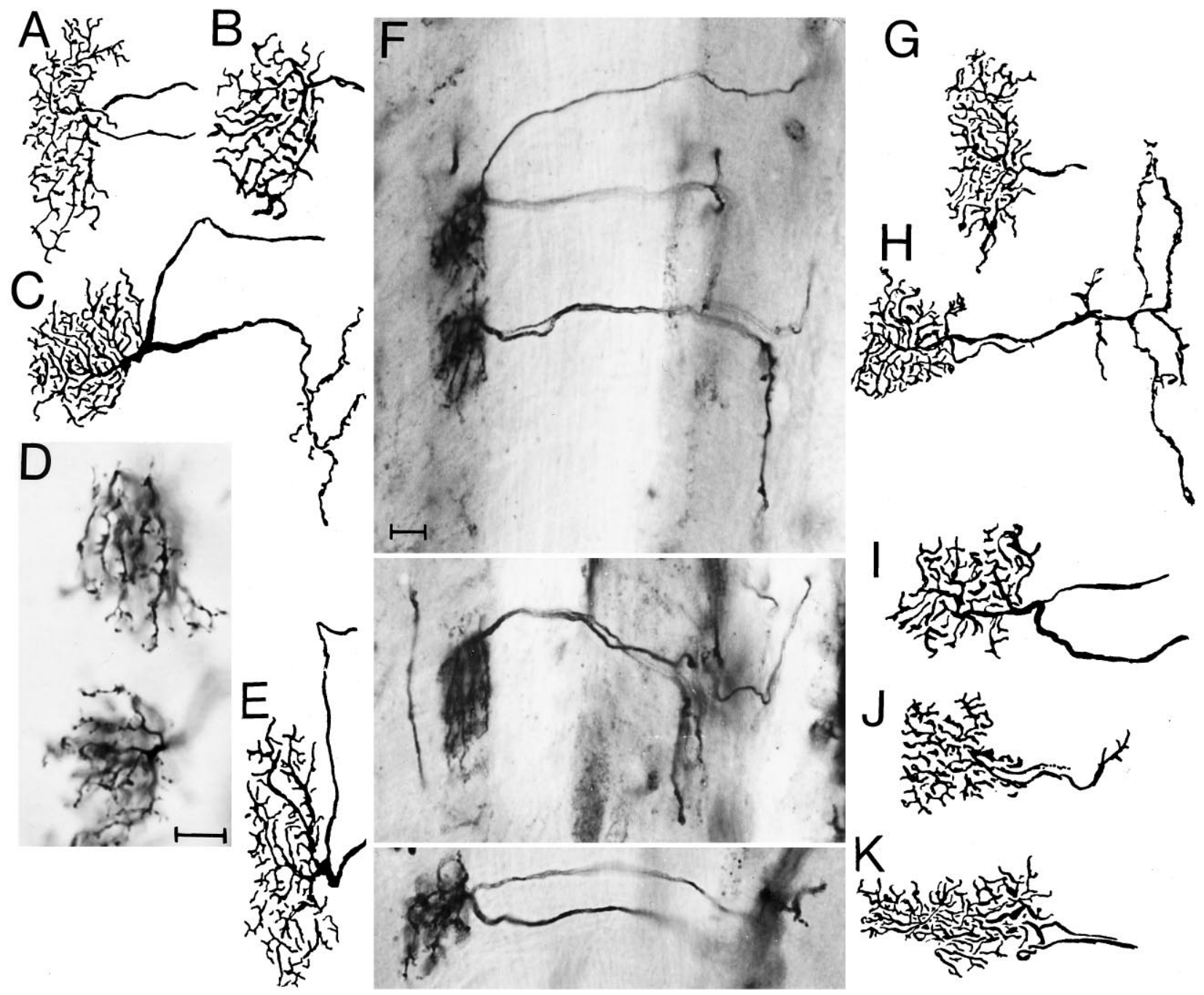

Figure 10. Reconstructions and photomicrographs of T5 neurons of seven brachyceran $(A-H)$ and three nematoceran $(I-K)$ species to show the remarkable morphological conservation of this type of nerve cell. $A$, Calliphorid; $B$, glossinid; $C$ and $D$, syrphid; $E$, asilid; $F$, bombyliid; $G$, dolichopodid; $H$, tabanid; $I$, simuliid; $J$, culicid; $K$, tipulid. Scale in $D$ (for all drawings), $E$ (for all half tones), $20 \mu \mathrm{m}$. The phylogenetically basal Nematocera as well as tabanids are characterized by narrower dendritic fields and a relatively thicker lobula stratum than the other species.

Golgi impregnations of asilids reveal that $\mathrm{T} 4$ and $\mathrm{T} 5$ all terminate at the levels of HS-like dendritic trees (Fig. 11B), which are more numerous than the usual set of three found in other brachycerans. T4 and T5 layering is also absent in the nocturnal, slow-flying culicids, the lobula plates of which lack discrete layers of HS and VS neurons typical of diurnal Diptera.

\section{DISCUSSION}

The phylogenetic organization of the Diptera (Fig. 2) is better understood than that of many other insect orders (McAlpine, 1989; Wood and Borkent, 1989; Woodly, 1989; Sinclair et al., 1993; Cumming et al., 1995), and there is considerable information about the variety of visually evoked flight behaviors (compare, for example, Dolichopodidae, Syrphidae, Muscidae, and Asilidae (Collett and Land, 1975; Tricca and Trujillo-Cenóz, 1980; Zeil, 1983b, 1986; Land, 1993a,b). However, attempts to identify neurons corresponding to the Hassenstein-Reichardt autocorrelation circuit for motion detection have been hampered by difficulty in isolating from among the 80 or so morphological species of neurons a subset to which could be ascribed the appropriate physiological properties and connections. By demonstrating that a limited number of cell types within the medulla are associated unambiguously with the lobula plate and are ubiquitous across dipteran taxa, we propose that, independent of body shape and flight biomechanics or behaviors, Diptera have evolved and retained a characteristic arrangement of uniquely identifiable neurons serving motion computation.

\section{Phylogenetic ubiquity of parallel pathways}

Light and Golgi-electron microscopical analyses of the lamina of Musca have demonstrated that the precise and invariant alignment of neuronal components at specific layers is a reliable indicator of functional contiguity (Campos-Ortega and Strausfeld, 1972, 1973; Strausfeld and Campos-Ortega, 1973, 1977). Macroscopic structures such as varicosities, blebs, or beads, all representing presynaptic sites, oppose spines and thorns, which represent postsynaptic specializations. In the medulla, depth measurements showing the coincidence of dendrites and terminals suggest, though cannot prove, levels of functional contiguity (Fig. 6). However, neurons are likely to have synaptic connections when they show consistent depth matching, independent of taxon specificity (Fig. 6). For example, Tm1 neurons of calliphorids and 


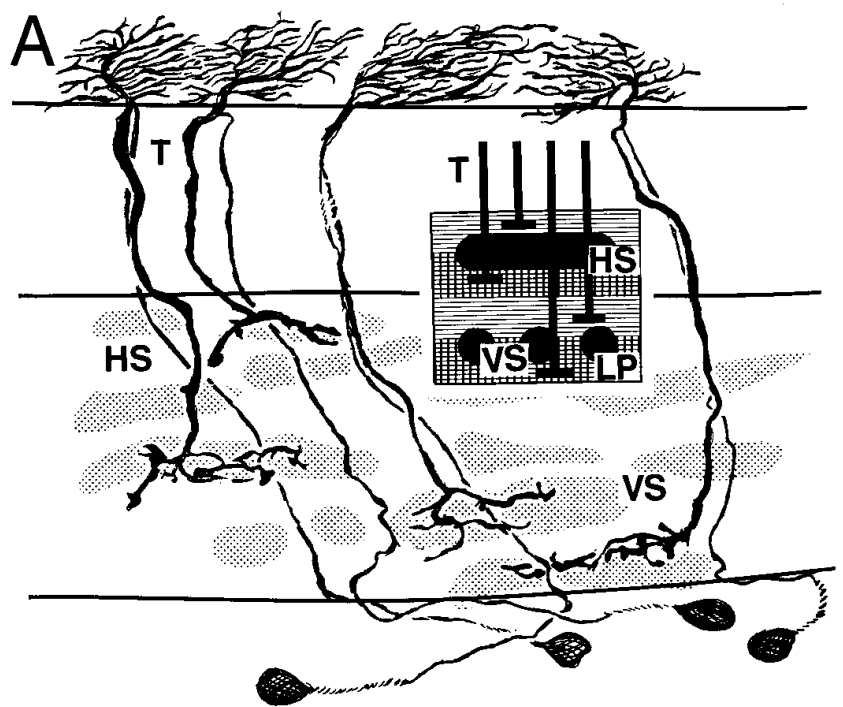

syrphids have outer processes between 12 and $58 \%$ of the outer medulla, whereas in asilids the homologous processes of Tm1 are between 5 and $50 \%$, and the depth of the asilid L2 is correspondingly shallow. Evidence for functional contiguity is further supported by densitometric measurements that provide, at finer resolution, matching peaks and troughs of dendritic spine density and corresponding presynaptic varicosities (Fig. 7). These methods of analysis have been applied to taxa that represent three distinct evolutionary lines within the Brachycera: the Calliphoridae and Glossinidae, the related Asilidae and Bombyliidae, and the Tabanidae.

Asilids and bombyliids have been compared from the same clade because of major differences between their lobula plates and flight styles. Asilidae are long-bodied raptors that use ballistic target-directed flight and lack large, vertical motion-sensitive cells (VS cells) in the lobula plate, which, in calliphorids, help stabilize gaze (Strausfeld, 1996). Bombyliids are hovering flies par excellence with conventional lobula plates having HS and VS cells that are comparable with those in calliphorids. Despite these differences, both depth averaging and densitometric measurements (Figs. 6, 7) demonstrate the tight layer coincidence of iTm to the L1 terminal and Tm1 to L2 and, at their terminals, iTm to T4 and $\mathrm{Tm} 1$ to T5. The results confirm observations of Golgi preparations in which these neurons are coimpregnated (Fig. 9).

\section{A special case: taxonomic variation among centrifugal neurons}

$\mathrm{C} 2 \mathrm{~s}$ are ubiquitous among the Brachycera and may be crucial in directional motion sensitivity, responding selectively to motion orientation (Douglass and Strausfeld, 1995). However, there is considerable cross-taxonomic variation among C2 neurons, as gauged by independent indices of morphological constancy epitomized by T4 and T5 neurons (Figs. 9, 10). A striking variation is in the size of the dendritic fields of $\mathrm{C} 2$, one in the inner medulla at $90-100 \%$ of its depth (except in bombyliids) and the other in the outer medulla at $90-100 \%$ of its depth (see Fig. $5 A-C$ ). In the closely related calliphorids and glossinids, these vertical dendrites extend through 3-6 columns to each side of the parent axon. This contrasts with the widely spreading vertical $\mathrm{C} 2$ dendrites in syrphids in the same clade (Fig. $5 C$ ) and the much smaller spreads in more basal taxa: the dolichopodids, bombyliids, and asilids. Sim- ilarly, in the clade of calliphorids, glossinids, and syrphids, the outermost presynaptic specializations of $\mathrm{C} 2$ comprise tightly packed varicosities at the level of the outermost swelling of L1. However, in asilids and dolichopodids, the outer component of $\mathrm{C} 2$ is a branched-axon collateral extending to neighboring columns as it does exaggeratedly in bombyliids.

Morphological variations among neurons that are evolutionarily conserved raise interesting questions about their functional significance. Is the orientation-selectivity of C2 (Douglass and Strausfeld, 1995) a consequence of its dendritic relationships with retinotopic afferents? If so, is orientation tuning qualitatively different in those taxa in which $\mathrm{C} 2$ dendrites have a small or longer passage through retinotopic columns? Similarly, if the interactions of $\mathrm{C} 2$ with neighboring columns underlie an essential component of the elementary motion-detecting circuit, then taxon-specific differences in the lateral extent of the medullary presynaptic component of $\mathrm{C} 2$ also may provide taxon-specific differences in spatial tuning. Recordings from $\mathrm{T} 5$ in different taxa might be revealing. In Phaenicia, T5 responses to directional motion show spatial phase-locked modulation (Douglass and Strausfeld, 1995). Would these be any different in species with larger or smaller $\mathrm{C} 2$ fields, thus reflecting differences in the number of columns involved in elementary computational processes?

Although taxon-specific morphologies might be of adaptive value to the performance of that individual, most of the anatomical variations described here reflect phylogenetic affinities and support the idea that conserved neurons actually show little variation (Figs. 5, 8). As evidenced by the outer components of $\mathrm{C} 2$ in the medulla, such variations, when they occur, seem to differentiate between taxa that are separated further, phylogenetically, than among taxa within a clade. Thus, when major variations do occur among close relatives, such as observed with $\mathrm{C} 2$ dendritic spreads (syrphids vs calliphorids), such variations should suggest, and be tested for, their functional relevance. In asilids, for example, two forms of iTms have been identified, one with dendrites restricted to a single column and the other with dendrites extending symmetrically to neighboring columns (Fig. 9). In both, their dendrites are densest at the outer specialization of L1 rather than at two levels, the deeper of which would include the lobed ending 
of L2. In simuliids, the iTm has dendrites that coincide with both L1 and L2, an organization reflecting the typical L1/L2 stratification in nematocerans (Melzer and Paulus, 1993).

Apart from these singular and minor exceptions, there is negligible variation in the relative layer relationships of the main cell types discussed here. This is exemplified by calliphorids and other members of the same suborder in which Tm1 is characterized by a narrow, elongated dendritic tree situated at the level of L2 terminals. Essentially the same arrangement is seen in tabanids despite a comb-like terminal in L2 that matches the dendritic stratification of Tm1 into four equal layers between 7 and $60 \%$. In asilids, L2 endings are relatively close to the outer surface of the medulla; Tm 1 dendrites correspondingly arise more distally in the medulla than they do in calliphorids but extend to the same $58-60 \%$ depth (Fig. 6).

\section{The functional significance of conserved neuronal pathways}

Several attempts have been made to match components of the optic lobes to features of the Reichardt-Hassenstein autocorrelation model for elementary motion detection. Activity-dependent ${ }^{3} \mathrm{H}$-2-deoxyglucose uptake (Buchner et al., 1984) localizes motioninduced activity to specific layers of the medulla, the outer layer of the lobula, and to the lobula plate. Retinal ablation gives rise to rapid transneuronal degeneration of the lobula plate and to destruction of the outermost stratum of the lobula, sparing its deeper levels (Strausfeld and Lee, 1991). Together, these findings suggest a rapid and distinct motion-sensitive pathway to the lobula plate connected to the retina by few synapses. The results suggest that the retina is linked to the lobula by more intermediate synapses and that lobula neurons respond to stimuli other than wide-field motion (Gilbert and Strausfeld, 1992).

The retina to lobula-plate pathway starts with the synaptic input from R1-R6 onto the LMCs L1 and L2. These are common to all taxa regardless of evolutionary "remodeling" of synaptic connections that are not apparent at the light microscopical level (Shaw and Meinertzhagen, 1986; Meinertzhagen and Shaw, 1989; Shaw and Moore, 1989) or that show some evidence of convergence (Shaw et al., 1989) or regional specialization of the R7 and R8 system at the lamina (Hardie, 1983). We have shown that the basic organization among the neurons from the level of the LMC terminals to the lobula plate is remarkably consistent, regardless of subtle differences in optic lobe architecture, receptor arrangements in ommatidia, or lamina synaptology. Separate roles for L1 and L2 in the optomotor pathway have been proposed on the basis of systematic differences in their diameters (Braitenberg and Hauser-Hohlschuh, 1972). The distinction of L1 and L2 is supported here by their morphological differences in the medulla and from density measurements that show L2 coincident with Tm1 and L1 coincident with iTm. Tm1 terminates at T5, and the deep varicosities from $\mathrm{iTm}$ are aligned with $\mathrm{T} 4$ dendrites. These relationships throughout the Brachycera and strongly implicated in the Nematocera support physiological evidence for two parallel motion-computing pathways (Douglass and Strausfeld, 1995, 1996). Four T4 cells, and probably two to four T5 cells, arise from each retinotopic column so that each visual sampling point is represented by six to eight bushy $\mathrm{T}$-cell endings segregating to four activity-dependent motion- and direction-sensitive levels in the lobula plate (Strausfeld and Lee, 1991). These coincide with motion- and direction-sensitive wide-field lobula-plate tangential neurons (Hausen and Egelhaaf, 1989). Similarly, two putative motion-sensitive pathways have been suggested from the results of activity-dependent uptake of ${ }^{3} \mathrm{H}$-2-deoxyglucose in Drosophila (Bausenwein and Fischbach, 1992a), in which sensitive densitometric techniques demonstrated different levels of accumulation in response to moving stripes. Elevated ${ }^{3} \mathrm{H}$-2-deoxyglucose in the inner stratum of the medulla, corresponding to the T4 level, accompanied elevated activity in two strata of the outer medulla, corresponding to the two levels of the bistratified L1 terminals. Likewise, motion-induced ${ }^{3} \mathrm{H}$-2-deoxyglucose accumulation in a level of the outer medulla, corresponding to the L2 terminal, and the arborization of $\mathrm{Tm} 1$ accompanied elevated activity in the Tm1/T5 stratum of the lobula (Bausenwein and Fischbach, 1992a,b). In these experiments, however, directional motion was not distinguished from nondirectional, whereas intracellular recordings suggest such a distinction between the L2-Tm1-T5 and the L1-iTm-T4 pathways (Douglass and Strausfeld, 1995, 1996).

\section{Phylogenetic ubiquity of elementary motion-detector neurons}

The present results demonstrate that, in the species examined, neurons suspected of being involved in elementary motion computation are phylogenetically ubiquitous. The two parallel pathways from the lamina to the lobula plate pathway seen in extant Diptera are ancestral and are unrelated to the flight performance, behavior, circadian habit, or corresponding physiology of a taxon (cf. Laughlin and Weckström, 1995). These conserved pathways suggest that elementary motion-detecting circuits evolved before the appearance in the Jurassic of flies with short antennae (Brachycera; Kovalev, 1981) and before the divergence of Brachycera and Nematocera, 223 million years BP (before present) in the late Triassic (Hennig, 1981).

The likelihood that these circuits even predate the divergence of Diptera from other major groups is suggested by observations of the moth Sphinx ligustri and the honeybee Apis mellifera. Both possess fly-like transmedullary neurons that are associated with T4- and T5-like elements (Strausfeld and Blest, 1970; Strausfeld, 1976) which, in bees, project deep into the undivided lobula (Strausfeld, 1976) and reach wide-field directional motionsensitive neurons (DeVoe et al., 1982). In Lepidoptera they reach directional motion-sensitive tangential neurons in the lobula plate (Wicklein, 1993). Coleoptera (beetles) are known from Permian deposits (260 million years BP) and, like the Diptera, their modern representatives have lobula plate neuropils.

\section{REFERENCES}

Bausenwein B, Fischbach K-F (1992a) Activity labeling patterns in the medulla of Drosophila melanogaster caused by motion stimuli. Cell Tissue Res 270:25-35.

Bausenwein B, Fischbach K-F (1992b) Separation of functional pathways in the fly's medulla: combination of 2-deoxyglucose studies with anatomical fine analysis. In: Nervous systems principles of design and function (Singh RN, ed), pp 223-239. New Delhi, India: Wiley Eastern.

Bodian D (1937) A new method for staining nerve fibers and nerve endings in mounted paraffin sections. Anat Rec 69:153-162.

Boschek CB (1971) On the fine structure of the peripheral retina and lamina ganglionaris of the fly, Musca domestica. Z Zellforsch Mikrosk Anat 118:369-409.

Braitenberg V (1967) Patterns and projections in the visual system of the fly. I. Retina-lamina projections. Exp Brain Res 3:271-298.

Braitenberg V, Hauser-Hohlschuh H (1972) Patterns of projections in the visual system of the fly. II. Quantitative aspects of second order neurons in relation to models of movement perception. Exp Brain Res 16:184-209.

Buchner E, Buchner S, Bülthoff I (1984) Deoxyglucose mapping of nervous activity induced in Drosophila brain by visual movement. I. Wild type. J Comp Physiol [A] 155:471-483. 
Buschbeck E, Strausfeld NJ (1993) Functional aspects of neuroanatomical variation in the dipteran optomotor pathway and the usage of neural characters as a basis for phylogeny inference. In: Proceedings of the 22nd Göttingen Neurobiology Conference (Elsner N, Beer H, eds), p 200. Stuttgart: Thieme.

Campos-Ortega JA, Strausfeld NJ (1972) Columns and layers in the second synaptic region of the fly's visual system: the case for two superimposed neuronal architectures. In: Information processing in the visual systems of arthropods (Wehner R, ed), pp 31-36. Berlin: Springer.

Campos-Ortega JA, Strausfeld NJ (1973) Synaptic connections of intrinsic cells and basket arborisations in the external plexiform layer of the fly's eye. Brain Res 59:119-136.

Collett TS, Land MF (1975) Visual control of flight behaviour in the hoverfly, Syritta pipiens L. J Comp Physiol [A] 99:1-66.

Cumming JM, Sinclair BJ, Wood DM (1995) Homology and phylogenetic implications of male genitalia in Diptera-Eremoneura. Entomol Scand 26:121-151.

DeVoe RD, Kaiser W, Ohm J, Stone LS (1982) Horizontal movement detectors of honeybees: directionally selective visual neurons in the lobula and brain. J Comp Physiol 147:155-170.

Douglass JK, Strausfeld NJ (1995) Visual motion-detection circuits in flies: peripheral motion computation by identified small-field retinotopic neurons. J Neurosci 15:5596-5611.

Douglass JK, Strausfeld NJ (1996) Visual motion-detection circuits in flies: parallel direction- and nondirection-sensitive pathways between the medulla and lobula plate. J Neurosci, in press.

Fischbach K-F, Dittrich APM (1989) The optic lobe of Drosophila melanogaster. A Golgi analysis of wild-type structure. Cell Tissue Res 258:441-475.

Franceschini N (1975) Sampling of the visual environment by the compound eye of the fly: fundamentals and applications. In: Photoreceptor optics (Snyder AW, Menzel R, eds), pp 98-125. Berlin: Springer.

Franceschini N, Riehle A, Le Nestour A (1989) Directionally selective motion detection by insect neurons. In: Facets of vision (Stavenga DG, Hardie RC, eds), pp 360-390. Berlin: Springer.

Frye MA, Olberg RM (1995) Visual receptive field properties of featuredetecting neurons in the dragonfly. J Comp Physiol [B] 177:569-578.

Gilbert C, Strausfeld NJ (1992) Small-field neurons associated with oculomotor and optomotor control in muscoid flies: functional organization. J Comp Neurol 316:72-86.

Gregory GE (1980) The Bodian Protargol technique. In: Neuroanatomical techniques (Strausfeld NJ, Miller TA, eds), pp 75-95. New York: Springer.

Gronenberg W, Strausfeld NJ (1990) Descending neurons supplying the neck and flight motor of Diptera: physiological and anatomical characteristics. J Comp Neurol 302:973-991.

Gronenberg W, Strausfeld NJ (1991) Descending pathways connecting the male-specific visual system of flies to the neck and flight motor. J Comp Physiol [A] 169:413-426.

Gronenberg W, Strausfeld NJ (1992) Premotor descending neurons responding selectively to local visual stimuli in flies. J Comp Neurol 316:87-103.

Hardie RC (1979) Electrophysiological analysis of fly retina I: Comparative properties of R1-6 and R7 and 8. J Comp Physiol 129:19-33.

Hardie RC (1983) Projection and connectivity of sex-specific photoreceptors in the compound eye of the male housefly Musca domestica. Cell Tissue Res 233:1-21.

Hassenstein B, Reichardt W (1956) Systemtheoretische Analyse der Zeit-, Reihenfolgen- und Vorzeichenauswertung bei der Bewegungsperzeption des Rüsselkäfers Chlorophanus. Z Naturforsch 11B:513-524.

Hausen K, Egelhaaf M (1989) Neural mechanisms of visual course control in insects. In: Facets of vision (Stavenga DG, Hardie RC, eds), pp 391-424. Heidelberg: Springer.

Hengstenberg R (1982) Common visual response properties of giant vertical cells in the lobula plate of the blowfly Calliphora erythrocephala. J Comp Physiol [A] 149:179-193.

Hennig W (1981) Insect phylogeny. New York: Wiley.

Hensler K (1992) Neuronal co-processing of course deviations and head movements in locusts. I. Descending deviation detectors. J Comp Physiol [A] 171:257-272.

Järvilehto M, Zettler F (1973) Electrophysiological-histological studies on some functional properties of visual cells and second order neurons of an insect retina. Z Zellforsch Mikrosk Anat 136:291-306.
Kirschfeld K (1967) Die Projecktion der optischen Umwelt auf das Raster der Rhabdomeren im Komplexauge von Musca. Exp Brain Res $3: 248-270$.

Kirschfeld K, Wenk P (1976) The dorsal compound eye of simuliid flies. Z Naturforch 31C:764-765.

Kovalev VG (1981) The oldest representatives of the Diptera with short antennae from the Jurassic in Siberia. Paleontol J 15:84-100.

Land MF (1993a) The visual control of courtship behavior in the fly Poecilobothrus nobilitatus. J Comp Physiol [A] 173:595-603.

Land MF (1993b) Chasing and pursuit in the dolichopodid fly Poecilobothrus nobilitatus. J Comp Physiol [A] 173:605-613.

Laughlin SB (1984) The roles of parallel channels in early visual processing by the arthropod compound eye. In: Photoreception and vision in invertebrates (Ali MA, ed), pp 457-481. New York: Plenum.

Laughlin SB, Weckström M (1995) Fast and slow receptors-a comparative study of the functional diversity of coding and conductances in the Diptera. J Comp Physiol [A] 172:593-609.

McAlpine JF (1989) Phylogeny and classification of the Muscomorpha. In: Manual of nearctic Diptera, Vol 13, Agriculture Canasa Monograph 32 (McAlpine JF, ed), pp 1397-1518.

Meinertzhagen IA, Shaw SR (1989) Evolution of synaptic connections between homologous neurons in insects: new cells for old in the optic lobe. In: Neural mechanisms of behavior (Erber J, Menzel R, Pflüger H-J, Todt D, eds), pp 124-126. Stuttgart: G Thieme Verlag.

Melzer RR, Paulus HF (1993) Neuroanatomische Studien am Sehsystem von Mücken (Diptera, Nematocera): ein Beitrag zur vergleichenden Analyse neuronaler Strukturen. Verh Dtsch Zool Ges 86:221.

Meyer E, Manute C, Streit P, Nässel DR (1986) Insect optic lobe neurons identifiable with monoclonal antibodies to GABA. Histochemistry 84:207-216.

Olberg RM (1981) Object and self-movement detectors in the ventral nerve cord of the dragonfly. J Comp Physiol [A] 141:327-334.

Olberg RM (1986) Identified target-selective visual interneurons descending from the dragonfly brain. J Comp Physiol [A] 159:827-840.

Ramon y Cajal S (1937) Recollections of my life (Recuerdos de mi vida), translated by Horne Craigie E, Cano J. Cambridge, MA: MIT.

Ramon y Cajal S, Sanchez D (1915) Contribucion al conocimiento de los centros nerviosos de los insectos. I. Retina y centros opticos. Trab Lab Invest Biol Univ Madrid 13:1-168.

Rind FC (1983) A directionally selective motion detecting neuron in the brain of a moth. J Exp Biol 102:153-171.

Shaw SR (1989) The retina lamina pathway in insects, particularly Diptera, viewed from an evolutionary perspective. In: Facets of vision (Stavenga DG, Hardie RC, eds), pp 187-212. Berlin: Springer.

Shaw SR (1990) The photoreceptor axon projection and its evolution in the neural superposition eyes of some primitive brachyceran Diptera. Brain Behav Evol 35:107-125.

Shaw SR, Meinertzhagen IA (1986) Evolutionary progression at synaptic connections made by identified homologous neurons. Proc Natl Acad Sci USA 83:7961-7965.

Shaw SR, Moore D (1989) Evolutionary remodeling in a visual system through extensive changes in the synaptic connectivity of homologous neurones. Vis Neurosci 3:405-410.

Shaw SR, Fröhlich A, Meinertzhagen IA (1989) Direct connections between the R7/8 and R1-6 subsystem in the dipteran visual system. Cell Tissue Res 257:295-302.

Sinclair BJ, Cumming JM, Wood DM (1993) Homology and phylogenetic implications of male genitalia in Diptera-Lower Brachycera. Entomol Scand 24:407-432.

Strausfeld NJ (1970) Golgi studies on insects. II. The optic lobes of Diptera. Philos Trans R Soc Lond [Biol] 258:175-223.

Strausfeld NJ (1971) The organization of the insect visual system (light microscopy). I. Projections and arrangements of neurones in the lamina ganglionaris of Diptera. Z Zellforsch Mikrosk Anat 121:377-441.

Strausfeld NJ (1976) Atlas of an insect brain. Heidelberg: Springer.

Strausfeld NJ (1980) The Golgi method: its application to the insects nervous system and the phenomenon of stochastic impregnation. In: Neuroanatomical techniques (Strausfeld NJ, Miller TA, eds), pp 131203. New York: Springer.

Strausfeld NJ (1996) Oculomotor control in flies: from muscles to elementary motion detectors. In: Neurons, networks, and motor behavior (Stein P, Stuart D, Grillner S, Selverston A, eds), Boston: MIT, in press. 
Strausfeld NJ, Bassemir UK (1985) Lobula plate and ocellar interneurons converge onto a cluster of descending neurons leading to neck and leg motor neuropil in Calliphora. Cell Tissue Res 240:16-40.

Strausfeld NJ, Blest AD (1970) Golgi studies on insects. I. The optic lobes of Lepidoptera. Philos Trans R Soc Lond [Biol] 258:81-174.

Strausfeld NJ, Braitenberg V (1970) The compound eye of the fly (Musca domestica): connections between the cartridges of the lamina ganglionaris. Z Vgl Physiol 70:95-104.

Strausfeld NJ, Campos-Ortega JA (1973) The L4 monopolar neuron: a substrate for lateral interaction in the visual system of the fly, Musca domestica. Brain Res 59:97-117.

Strausfeld NJ, Campos-Ortega JA (1977) Vision in insects: pathways possibly underlying neural adaptation and lateral inhibition. Science 195:894-897.

Strausfeld NJ, Lee JK (1991) Neuronal basis for parallel visual processing in the fly. Vis Neurosci 7:13-33.

Strausfeld NJ, Nässel DR (1980) Neuroarchitectures of brain regions that subserve the compound eyes of Crustacea and insects. In: Handbook of sensory physiology, Vol VII/6B, Comparative physiology and evolution of vision in invertebrates (Autrum H, ed), pp 1-132. Berlin: Springer.

Torre V, Poggio T (1978) A synaptic mechanism possibly underlying directional selectivity to motion. Proc R Soc Lond [Biol] 202:409-416.

Tricca G, Trujillo-Cenóz O (1980) The sexual behavior of the robber-fly Mallophora ruficauda Wied (Asilidae, Asilinae) in normal and experimental conditions. Physiol Behav 25:627-632.
Trujillo-Cenóz O, Bernard GD (1972) Some aspects of the retinal organization of Sympycnus lineatus Loew (Diptera, Dolichopodidae). J Ultrastruct Res 38:149-160.

Watson ADH, Hardt M (1996) Distribution of synapses on two local auditory interneurons ON1 and ON2 in the prothoracic ganglion of the cricket: relationships with GABA-immunoreactive neurons. Cell Tissue Res 283:231-246.

Wicklein M (1993) Motion-sensitive interneurons in the lobula plate of Macroglossum stellatarum. In: Gene-brain-behavior (Elsner N, Heisenberg M, eds), p 366. Proceedings of the 21st Göttingen Neurobiology Conference. Stuttgart: Thieme.

Wood DM, Borkent A (1989) Phylogeny and classification of the Nematocera. In: Manual of nearctic Diptera, Sec 13, Agriculture Canasa Monograph 32 (McAlpine JF, ed), pp 1333-1370.

Woodly NE (1989) Phylogeny and classification of the "Orthorrhaphous" Brachycera. In: Manual of nearctic Diptera, Sec 13, Agriculture Canasa Monograph 32 (McAlpine JF, ed), pp 1371-1395.

Zeil J (1979) A new kind of neural superposition eye: the compound eye of male Bibionidae. Nature 278:240-250.

Zeil J (1983a) Sexual dimorphism in the visual system of flies: the compound eye and neural superposition in Bibionidae (Diptera). J Comp Physiol [A] 150:379-393.

Zeil J (1983b) Sexual dimorphism in the visual system of flies: the divided brain of male Bibionidae (Diptera). Cell Tissue Res 229:591-610.

Zeil J (1983c) Sexual dimorphism in the visual system of flies: the free flight behavior of male Bibionidae (Diptera). J Comp Physiol 150:395-412.

Zeil J (1986) The territorial flight of male houseflies (Fannia canicularis L). Behav Ecol Sociobiol 19:213-219. 